\title{
miR-151-5p alleviates corneal allograft rejection by activating PI3K/AKT signaling pathway and balancing Th17/Treg after corneal transplantation via targeting IL-2Ra
}

\author{
Qian Cao, Yunchuan Li, Yong Li, Lan Li \\ Department of Ophthalmology, The Affiliated Calmette Hospital of Kunming Medical University, Kunming, China \\ Contributions: (I) Conception and design: L Li; (II) Administrative support: L Li; (III) Provision of study materials or patients: Q Cao, L Li; (IV) \\ Collection and assembly of data: Q Cao, Y Li, Y Li; (V) Data analysis and interpretation: Q Cao, Y Li, Y Li; (VI) Manuscript writing: All authors; (VII) \\ Final approval of manuscript: All authors. \\ Correspondence to: Lan Li. Department of Ophthalmology, The Affiliated Calmette Hospital of Kunming Medical University, No. 1228 Beijing Road, \\ Panlong District, Kunming 650000, China. Email: lanli2021@163.com.
}

Background: Worldwide, corneal transplantation (CT) is the most common type of tissue replacement and the increased rate of corneal graft rejection (CGR) after CT is a critical problem. Corneal endothelium cells (CECs) are often targets of the immune response mediated by graft-attacking effector $\mathrm{T}$ cells. However, the molecular mechanism underlying CGR remains poorly understood.

Methods: The differentially expressed microRNAs (miRNAs) and mRNA of graft-fail corneas were measured by transcriptome sequencing (RNA-Seq). real-time quantitative polymerase chain reaction was used to measure gene expression levels. Western blot and immunofluorescence staining were used to measure protein expression levels. Kaplan-Meier survival curves were constructed to assess corneal graft survival. Hematoxylin and eosin staining was used for histopathological examination. CCK-8 and ELISA staining were used to detect cell viability and inflammatory cytokines levels, respectively. Flow cytometry was used to detect cell apoptosis and the population of Treg and Th17. Transwell migration and wound-healing assays were used to measure cell migration.

Results: We identified 453 miRNAs and 4,279 mRNAs aberrant expression in the corneas showing CGR. The differentially expressed miR-151-5p and its potential target gene [interleukin 2 receptor subunit alpha $(I L-2 R a)]$ were selected from the RNA-Seq microarrays. The levels of miR-151-5p and IL-2Ra were respectively downregulated and upregulated in the CGR. The luciferase activity assay suggested that IL-2Ra is a target of miR-151-5p in $293 \mathrm{~T}$ cells. In addition, the miR-151-5p inhibitor, si-IL-2Ra, and oe-IL-2Ra transfection tests in CECs further confirmed that miR-151-5p downregulation and IL-2Ra overexpression promoted apoptosis of CECs and inhibited CEC migration, tight junction-related protein ZO-1 and Claudin-5 expression, and PI3K/AKT signaling pathway activity; however, downregulation of IL2Ra abolished the inhibitor effect of miR-151-5p. Similarly, upregulation of miR-151-5p alleviated CGR via activation of the PI3K/AKT signaling pathway and balancing of Th17/Treg, and upregulation of IL-2Ra abolished the alleviating effect of miR-151-5p.

Conclusions: Upregulation of miR-151-5p alleviated CGR by activating the PI3K/AKT signaling pathway and balancing Th17/Treg via targeting of IL-2Ra, which contributes to improving the results of CT.

Keywords: Corneal transplantation (CT); corneal allograft rejection (CGR); miR-151-5p/IL-2Ra; PI3K/AKT signaling pathway; Th17/Treg

Submitted Feb 24, 2021. Accepted for publication Aug 26, 2021.

doi: 10.21037/atm-21-2054

View this article at: https://dx.doi.org/10.21037/atm-21-2054 


\section{Introduction}

Worldwide, approximately 216.6 million individuals have moderate or severe vision impairment, and 4.5 million have moderate to severe vision impairment secondary to loss of corneal clarity (1). Corneal transplantation (CT), which is the most frequently performed transplant worldwide, restores visual function when there is severe visual impairment caused by a corneal disease. However, the immune rejection-induced graft failure is a critical issue for CT (2). The CT rejection rate is reported to range from $10 \%$ to $30 \%(3,4)$. Moreover, in high-risk recipients rejection rates are up to $50 \%(4,5)$. Corticosteroids are the commonly used treatment for acute rejection but can cause adverse effects $(6,7)$. Thus, improving our understanding of the molecular basis of corneal graft rejection (CGR) is important for its prevention or treatment.

CGR can occur in three cell layers of the cornea (epithelium, stroma, or endothelium), and endothelial rejection is the most prevalent vision-threatening form (8). Corneal endothelium cells (CECs) are often the targets of the immune response mediated by graft-attacking effector T cells (9). When the number of CECs decreases beyond a certain threshold, the graft fails by decreasing corneal graft transparency $(10,11)$. The balance of regulatory $T$ cell-T helper 17 cells (Treg-Th17) is important in immune homeostasis and the ratio plays a vital role in promoting allogeneic corneal graft survival in mice (12). Treg cells have been shown to attenuate CGR by modulating immune responses, and a shift toward the stabilization of Treg populations can promote CEC survival (13). Disturbance of the Treg-Th17 axis is one of the key points in CEC death following CGR. However, whether CGR leads to CEC death remains largely unknown.

The phosphatidylinositol 3-kinase (PI3 K)/protein kinase B (AKT) signaling pathway is involved in a wide range of biological processes, including immune responses, by modulating the Treg/Th17 ratio $(14,15)$. In tissue transplantation, one of the most important factors in the rejection response is dysregulation of PI3K/AKT. Recent research suggested that PI3K/AKT signaling pathway activation prolonged long-term kidney allograft survival via carbamylated erythropoietin (14). Notably, Kyoto Encyclopedia of Genes and Genomes (KEGG) pathway analysis has shown that the differentially expressed miRNAs (DEMs) crucially enriched pathway are related to PI3K/ AKT signaling pathway in allograft corneas versus isograft corneas (16), while another study indicated that PI3K/AKT signaling pathway activation promoted CECs proliferation and wound healing $(17,18)$, suggesting that activation of the PI3K/AKT signaling pathway would promote CEC survival. Additionally, the PI3K/AKT signaling pathway has been implicated in many biological processes, including cell cycle, migration, proliferation and apoptosis $(19,20)$. However, how the PI3K/AKT signaling pathway functions in CGR remains unclear.

MicroRNAs (miRNAs) are a single-stranded and small non-coding RNA sequences that silence gene expression posttranscriptionally by binding to the 3 ' untranslated regions of target mRNAs (21). It is notable that miRNAs have a significant effect on the rejection response after tissue transplantation $(22,23)$. For example, miR-155-5p and miR$181 \mathrm{a}-5 \mathrm{p}$ may be useful biomarkers of the rejection response in kidney transplantation $(24,25)$. miR-122 ameliorates corneal allograft rejection through downregulation of cytoplasmic polyadenylation element-binding protein-1 expression (26). Although previous studies identified many aberrantly expressed miRNAs in CGR (16), the network of miRNA and mRNA in CGR is still unclear. In particular, the molecular functions of miR-151-5p and its potential target gene, interleukin 2 receptor subunit alpha $(I L-2 R a)$, require further research.

This study aimed to establish the miRNA and mRNA expression profiles of the corneal tissues from failed and donor corneal grafts using transcriptome sequencing assay, with the goal of characterizing the pathogenesis of rejection responses in CT. We present the following article in accordance with the ARRIVE reporting checklist (available at https://dx.doi.org/10.21037/atm-21-2054).

\section{Methods}

\section{Animals and CT}

Adult female Sprague-Dawley rats, weighing 220-250 g without eye disease, were obtained from Hunan SJA Laboratory Animal Co., Ltd. (Certificate no. 43004700043639, China). All rats were housed individually with light-dark $(12: 12)$ cycles at $22{ }^{\circ} \mathrm{C}$ with $50 \%$ humidity, and received ad libitum food and water. Experiments were performed under a project license (No. YLS202018) granted by the Animal Experimental Ethical Inspection of the Affiliated Calmette Hospital of Kunming Medical University, in compliance with the management requirements of the Animal Management Association of the Affiliated Calmette Hospital of Kunming Medical 
University for the care and use of animals. The right eye was used in the model, and the left eye was untouched to prevent any effects on the postoperative food intake of the rats. A protocol was prepared before the study without registration.

The rat model of allogenic penetrating keratoplasty with donation after cardiac death was established according to the previously described technique (27). The eyelid sutures were cut $24 \mathrm{~h}$ after the operation, and then observed and photographed under a stereomicroscope (Olympus, Tokyo, Japan). The rats were randomly assigned to four groups: the sham group, CGR group, miR-151 mim group (treatment of the CGR rats with agomiR-151-5p was as described previously (26). In brief, the operated right eye had agomiR$151-5 \mathrm{p}(5 \mathrm{nmol})$ applied 4 times daily for 30 days, and miR$151 \mathrm{mim}+\mathrm{oe}-\mathrm{IL}-2 \mathrm{R} \alpha$ group [treatment of the CGR rats with agomiR-151-5p and IL-2Ra overexpression lentiviral vector (oe-IL-2Ra, Guangzhou RiboBio Biotechnology Co., Ltd., Guangzhou, China)]. The survival of the grafts in the each group (15 rats each group) was observed daily for 30 days post-treatment. Successful modeling criteria were: no graft wound dehiscence, anterior chamber infection, intraocular infection and other complications occurring within 3 days after operation. Animals with infection, hyphema, and cataract or other surgical complications were excluded from this study. Observations were made daily for the first week after operation. The opacity index, edema index and neovascularization index of the corneal graft were recorded and scored according to the Larkin DF standard (Table S1). The sum of the three scores was the rejection index (RI), and corneal rejection was defined as $\mathrm{RI} \geq 6$ according to a previous study (28).

For transcriptome sequencing (RNA-Seq) analysis, the rats were humanely killed under anesthesia 14 days after operation $(R I \geq 6)$, then the rejected corneal allografts $(n=36)$ were collected and total RNA was extracted for RNA-Seq analysis. Donor corneal grafts $(n=36)$ were used as controls to compare the relative expression level of RNA in the corneal grafts of the rejection group. RNA-Seq analysis was performed by Hangzhou Lianchuan Biotechnology Co., Ltd. (Hangzhou, China).

\section{Cell culture and transfection}

The CEC cell line B4G12 was purchased from the Beijing Beina Chuanglian Biotechnology Research Institute (Beijing, China) and cultured in DMEM containing $10 \%$ fetal bovine serum (FBS) and $50 \mathrm{U} / \mathrm{mL}$ penicillin and streptomycin antibiotics at $37{ }^{\circ} \mathrm{C}$ and $5 \% \mathrm{CO}_{2}$ in an incubator. The B4G12 cells was cultured with $50 \mathrm{ng} / \mathrm{mL}$ insulin-like growth factor 1 (IGF-1; MedChemExpress, Monmouth Junction, NJ) for $60 \mathrm{~min}$. The siRNA of $I L-2 R a$ (si- $I L-2 R a$; sense: 5'-CGTAAATACACAACACACACAC TCT-3'), pcDNA, and $I L-2 R a$ overexpression plasmid (oe$I L-2 R a)$ (GenePharma, Shanghai, China) were transfected into B4G12 cells. The miR-151-5p mimics, inhibitors and corresponding negative control were synthesized from Ribobio (Guangzhou, China), and finally transfected with Lipofectamine 2000 reagent (Invitrogen, CA, USA). The efficiency of transfection was detected after $48 \mathrm{~h}$ using realtime quantitative PCR (RT-qPCR).

\section{Histological evaluation}

After anesthesia, recipient corneas from three rats per group were harvested and embedded in paraffin on day 14 postgrafting. The samples were fixed with $10 \%$ formalin and normally embedded in paraffin, which was sliced at $5 \mu \mathrm{m}$ for hematoxylin and eosin staining.

\section{Immunofluorescent assay}

B4G12 cells were triple washed with prewarmed phosphatebuffered saline (PBS) and fixed in 4\% paraformaldehyde at room temperature for $20 \mathrm{~min}$. B4G12 cells were blocked with $5 \%$ bovine serum albumin in PBS for $1 \mathrm{~h}$ at room temperature and then incubated with primary antibody (rabbit anti-mouse Claudin-5, 1:50, and rabbit anti-mouse ZO-1, 1:100, Abcam, MA, USA) at $4{ }^{\circ} \mathrm{C}$ overnight. Cells were washed three times with PBS and incubated with secondary antibody (goat anti-rabbit IgG, 1:100, Abcam, USA) at room temperature in the dark for $1 \mathrm{~h}$. The cell nucleus was stained using DAPI. The slide was sealed and observed with Nikon Eclipse 80i microscope (Nikon, Tokyo, Japan).

\section{Allograft assessment of graft survival}

All grafts were examined every other day for 30 days, using a slit-lamp biomicroscope. To exclude primary graft failure, grafts with RI scores $\geq 6$ at 1 week after transplantation were excluded, including infection, hyphema, and cataract or other surgical complications.

\section{$R N A$ extraction and $R T-q P C R$}

Total RNA was isolated from the corneal tissues and B4G12 
cells using Trizol Reagent (Invitrogen) following the manufacturer's instructions. The first-strand cDNA of the total RNA was synthesized according to the instructions of the First-Strand cDNA Synthesis kit (BioTeke, Beijing, China). RT-qPCR was subsequently performed using the $2 \times$ Plus SYBR real-time PCR mixture (BioTeke) following the manufacturer's instructions. The RT-qPCR experiments were carried out in the QuantStudioTM 5 system (Thermo Scientific, DE, USA) under the following thermocycling conditions: pre-denaturation at $94{ }^{\circ} \mathrm{C}$ for $2 \mathrm{~min}, 40$ cycles at $94{ }^{\circ} \mathrm{C}$ for $15 \mathrm{~s}$, and annealing at $60{ }^{\circ} \mathrm{C}$ for $30 \mathrm{~s}$. After each reaction, a melting curve analysis was conducted to ensure consistency and specificity of the amplified product. Relative expression levels were calculated by the $2^{-\Delta \Delta \mathrm{Cq}}$ method (29) and normalized to the internal reference genes GAPDH (mRNA) and U6 (miRNA). The primers are listed in Table S2.

\section{Cell viability assay}

B4G12 cell viability was determined using the Cell Counting Kit-8 (CCK-8, Dojindo Molecular Technologies, MD, USA). Briefly, cells were seeded in 96-well plates in $5 \% \mathrm{CO}_{2}$ at $37{ }^{\circ} \mathrm{C}, 10 \mu \mathrm{L}$ CCK-8 solution was added to each well and the plates were cultivated for $1 \mathrm{~h}$. Finally, changes of absorbance were determined at $450 \mathrm{~nm}$ utilizing a microplate spectrophotometer (BioTeke).

\section{Detection of cell apoptosis}

Apoptosis was measured by an Annexin V combined fluorescein isothiocyanate/propidine iodide (FITC/PI; Solarbio, Beijing, China) flow cytometry analysis. Briefly, B4G12 cells were collected using cold PBS and then cultured with $10 \mu \mathrm{L}$ Annexin-V-FITC/PI (1:1) in the dark for $15 \mathrm{~min}$. Flow cytometry analysis was carried out in a FACS Verse flow cytometer (Becton Dickinson Biosciences, NJ, USA) and FlowJo software (version 10; Treestar, OR, USA).

\section{Cell migration assay}

Cell migration assay was performed using a transwell system (Millipore, MA, USA). In brief, B4G12 cells in DMEM medium without FBS were plated in the upper chamber, while the lower chamber was filled with DMEM medium containing $10 \% \mathrm{FBS}$. After incubation at $37^{\circ} \mathrm{C}$ for $24 \mathrm{~h}$, non-migrated cells in the upper chamber were removed, and migrated cells in the lower chamber surface were treated with $4 \%$ paraformaldehyde and with $0.1 \%$ crystal violet at room temperature for $15 \mathrm{~min}$. Each chamber was photographed using the Lionheart ${ }^{\mathrm{TM}} \mathrm{FX}$ automated live cell imager and the number of migrated cells was counted in three random fields using a light microscope (Olympus, Tokyo, Japan).

\section{Wound-bealing assay}

Cells were seeded in 6-well plates (90-95\% confluent) and cultured for $48 \mathrm{~h}$ until they reached full confluence. The confluent monolayers were scratched with $200-\mu \mathrm{L}$ pipette tips, and then the cells were cultured in DMEM medium without FBS for $24 \mathrm{~h}$. The cultures were observed using microscopy at 0 and $24 \mathrm{~h}$ and photographed using the Lionheart ${ }^{\mathrm{TM}} \mathrm{FX}$ automated live cell imager (BioTeke).

\section{Western blot assay}

The proteins of corneal tissues and B4G12 cells were extracted and determined according to standard protocols of protein extraction and bicinchoninic acid protein assay kits respectively (Pierce Biotechnology, USA). The total protein in the supernatant ( $30 \mu \mathrm{g} /$ well) was separated by SDS-PAGE (10\%) and then transferred to a polyvinylidene difluoride membrane and blocked with $5 \%$ skimmed milk. Subsequently, membranes were incubated with primary antibodies (all obtained from Abcam, USA): IL-2Ra (1:200; no. ab231441), p-PI3K (1:1,000; no. ab182651), PI3K (1:2,000; no. ab154598), p-AKT (1:1,000; no. ab38449), AKT (1:5,000; no. ab8805), ZO-1 (1:1,000; no. ab276131), Claudin-5 (1:5,000; no. ab172968) and $\beta$-Actin (1:5,000; no. ab8226) overnight at $4{ }^{\circ} \mathrm{C}$. After washing three times with TBST, the membranes were incubated with goat alkaline phosphatase-labeled anti-rabbit antibody $(1: 1,000$, Cell Signaling Technology, USA). The immunoreactive bands were visualized using an enhanced chemiluminescence reagent (Beyotime, Beijing, China). The blots were semiquantified by image $\mathrm{J}$ software 1.47 .

\section{Dual-luciferase reporter assays}

We constructed reporter vectors that included wildtype and mutant type binding sites of $I L-2 R a$ sequences, named as WT- $I L-2 R a$ and MUT- $I L-2 R a$, respectively, and cotransfected this vectors with miR-151-5p mimics, inhibitors and corresponding negative control into $293 \mathrm{~T}$ cells (Bank of Type Culture Collection of the Chinese 
Academy of Sciences). At $48 \mathrm{~h}$ after transfection, the dualluciferase reporter assay system (Promega) was used to detected luciferase activity following the manufacturer's protocol.

\section{Enzyme-linked immunosorbent assay (ELISA)}

The collection and storage of aqueous humor samples were performed as previously described (30). The B4G12 cellfree culture supernatant was collected after treatment, according to the instruction manual of the ELISA kit (Abcam, USA). The level of inflammatory cytokines (IL$1 \beta$, IL-2, IL-6, TNF- $\alpha$, and INF- $\gamma$ ) was measured using a micro plate spectrophotometer (BioTek Instruments, USA) at $450 \mathrm{~nm}$ optical density.

\section{Th17 and Treg populations}

Peripheral blood mononuclear cells (PBMCs) from three rats randomly selected from each group were separated using lymphocyte separation liquid (Multi Sciences, Hangzhou, China) following the manufacturer's instructions. Th17 (CD4 $\left.4^{+} / \mathrm{IL}-17^{+}\right)$and Treg (CD25 $/$ $\mathrm{FOXP}^{+}$) populations were determined by flow cytometry in a FACS Verse flow cytometer (BD Biosciences) using FlowJo-10.0 software (Treestar, USA).

\section{Statistical analysis}

All data were analyzed via Graphpad 7.0 (USA) and expressed as mean \pm standard deviation (SD). Corneal graft survival is presented by Kaplan-Meier survival curves. Multigroup comparisons were performed using one-way analysis of variance followed by Dunett's test. Comparisons between groups were performed using the least significant difference test. $\mathrm{P}<0.05$ was considered statistically significant.

\section{Results}

\section{Integrated analysis of differentially expressed miRNA and $m R N A$}

To determine the levels of mRNA and miRNA in CGR, we performed mRNA and miRNA profiling in graft-fail and graft-successful corneas. In total, $453 \mathrm{miRNA}$ and 5,485 mRNA transcripts were aberrantly expressed in graft-fail corneas versus graft-successful corneas (Figure $1 \mathrm{~A}$ and Figure S1A, respectively). Moreover, the heatmaps of identified DEMs and differentially expressed mRNAs (DEGs) are presented in Figure $1 B$ and Figure S1B, respectively, with some of the DEMs validated in both graft corneas when we detected 10 randomly selected DEMs (Figure 1C). Gene ontology (GO) analysis suggested that the DEMs have crucial roles in regulating integral components of the membrane and plasma membrane (Figure 1D), and the DEGs have crucial roles in angiogenesis (Figure S1C). KEGG pathway enrichment analysis suggested that the DEMs crucially enriched pathways were related to cell adhesion molecules and natural killer cell-mediated cytotoxicity (Figure $1 E$ ), and the DEGs most enriched pathways were related to the PI3K/ AKT signaling pathway and Th17 cell differentiation, which are important in modulating CGR (Figure S1D). We were interested in Th17 cell differentiation after CGR. Hence, Th17 cell differentiation related to the DEMs was selected, and RT-qPCR was conducted to examine the expression of the top 10 DEMs. As shown in Figure $1 F$, 4 and 6 DEMs were downregulated and upregulated, respectively. We focused on miR-151-5p because it is one of the most differentially expressed DEMs in CGR. MiRNAmRNA interaction analysis showed that $I L-2 R a$ and Prkcq are putative targets of miR-151-5p (Figure 1G), and that $I L-2 R a$ expression negatively correlated with miR-151-5p expression (Figure 1H). IL-2Ra is a subunit of IL-2R, which is specific for IL-2R (31). IL-2Ra reportedly regulates the Treg/Th17 ratio (32) and is associated with rejection in tissue transplant patients $(33,34)$. Therefore, we focused on the miR-151-5p/IL-2Ra axis for detailed research into their roles in CGR of CT.

\section{Involvement of MiR-151-5p in proliferation and migration of B4G12 cells}

To determine the functions of miR-151-5p in B4G12 cell proliferation and migration, we silenced miR-151-5p by using its inhibitors. The expression of miR-151-5p was effectively knockdown (Figure 2A). MiR-151-5p knockdown significantly reduced the vitality of B4G12 cells compared with the negative control (NC) group (Figure $2 B$ ). Apoptosis of B4G12 cells was significantly elevated after silencing miR-151-5p (Figure 2C). By contrast, miR-151$5 \mathrm{p}$ knockdown significantly reduced B4G12 cell migration (Figure 2D,2E). Interestingly, GO and KEGG pathway analysis found miR-151-5p was also involved in the PI3K/ AKT signaling pathway (35). We further examined the activation of the PI3K/AKT signaling pathway, using 
A

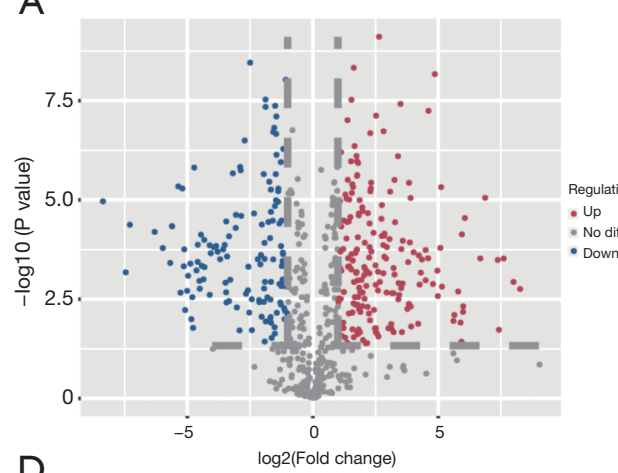

D

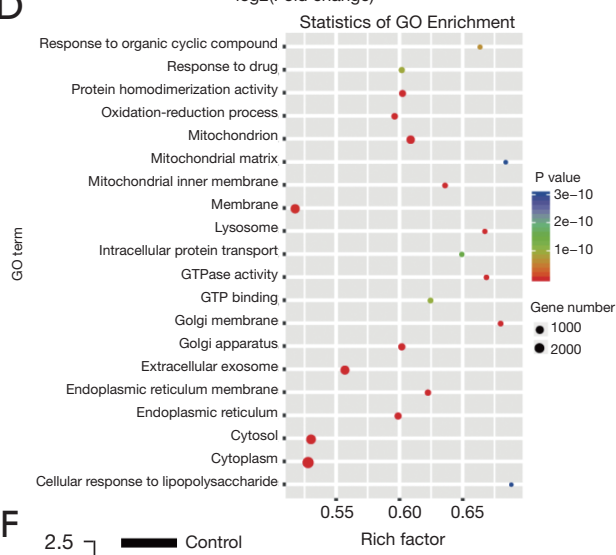

$\mathrm{F}$

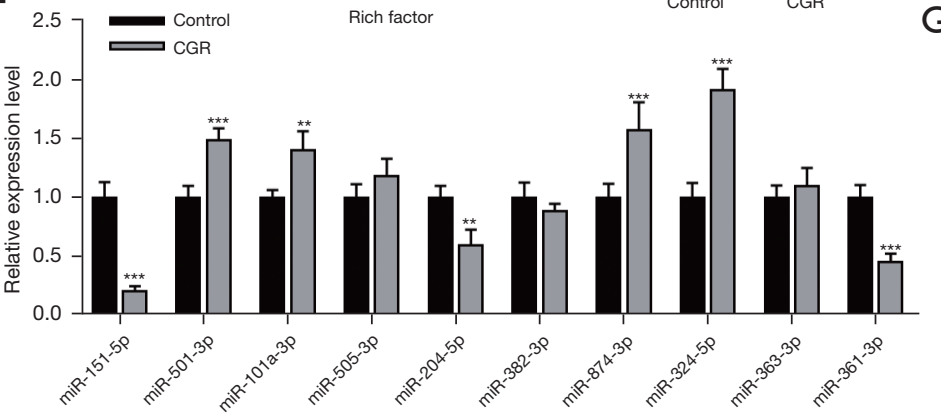

B

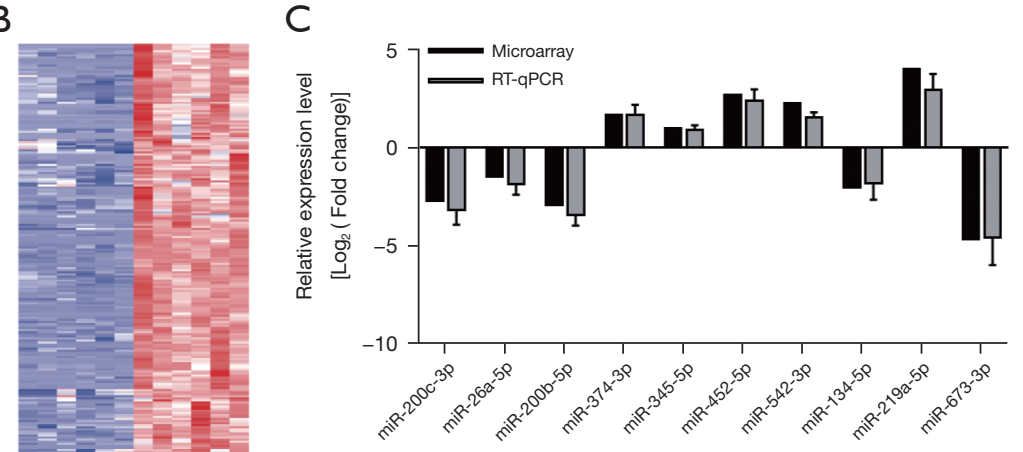

$\mathrm{E}$

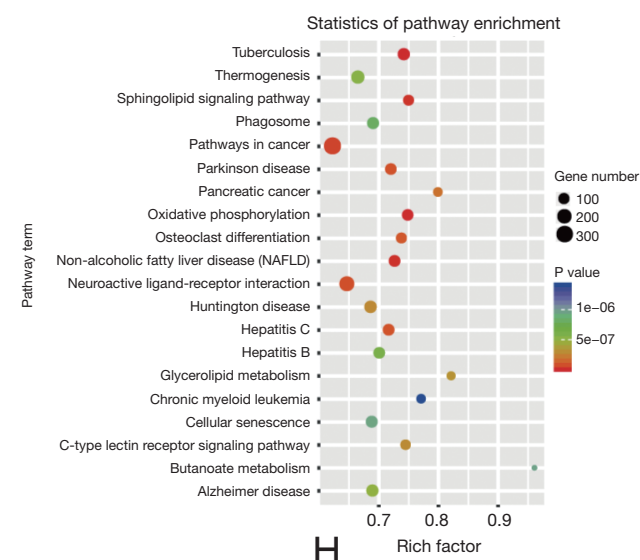

G

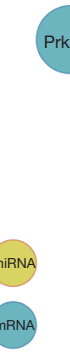

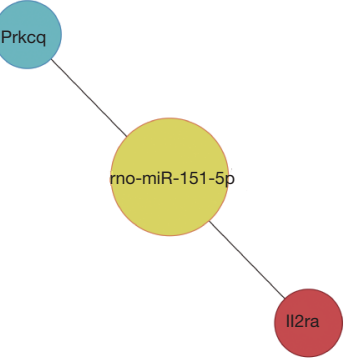

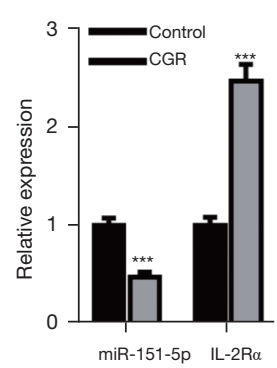

Figure 1 Integrated analysis of differentially expression miRNAs and mRNA. (A) Volcano plot of DEMs. X-axis indicates $\log 2$ (fold change), Y-axis indicates $-\log 10$ (P value). Blue represents downregulated miRNAs. Red represents upregulated miRNAs. Gray indicates no significantly differentially expressed miRNAs. (B) Heat map of differentially expressed miRNAs $(\mathrm{P}<0.05)$. There are 81 miRNAs with a significant change in CGR, including 249 and 204 upregulated and downregulated, respectively. (C) RT-qPCR detected DEMs expression in CGR, which was calculated using the $2^{-\Delta \Delta C q}$ method and is presented as the $\mathrm{n}$-fold change compared with control (n=6). (D) Top 20 enriched GO biological processes of DEMs. (E) Top 20 enriched KEGG pathways of DEMs. (F) Expression of the top 10 potential Th17 cell differentiation pathways related to DEMs detected by RT-qPCR ( $\mathrm{n}=6)$. (G) miR-151-5p-related miRNA-mRNA negative correlation network. (H) miR-151-5p and IL-2Ra expressions measured by RT-qPCR ( $\mathrm{n}=6) .{ }^{* *}, \mathrm{P}<0.01$ compared with control; ***, $\mathrm{P}<0.001$ compared with control. CGR, corneal graft rejection; DEMs, differentially expressed miRNAs; GO, gene ontology; KEGG, Kyoto Encyclopedia of Genes and Genomes; miRNAs, microRNAs; RT-qPCR, real-time quantitative PCR.

Western blotting. Notably, miR-151-5p knockdown significantly reduced $\mathrm{p}-\mathrm{PI} 3 \mathrm{~K}$ and $\mathrm{p}-\mathrm{AKT}$ expressions, but did not affect PI3K and AKT expressions (Figure $2 F$ ). Additionally, miR-151-5p knockdown remarkably increased the levels of inflammatory cytokines IL-6, IL-1 $\beta$, TNF- $\alpha$, and IFN- $\gamma$ (Figure 2G). Importantly, miR-151-5p depletion dramatically reduced tight junction-related protein $\mathrm{ZO}-1$ and Claudin-5 expressions (Figure $2 \mathrm{H}$ ). Furthermore, 


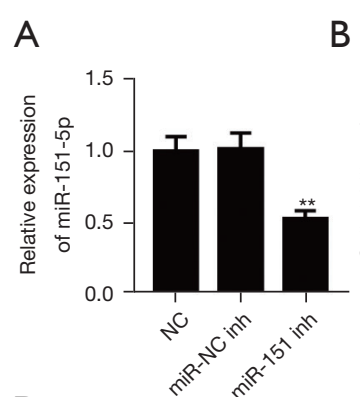

D
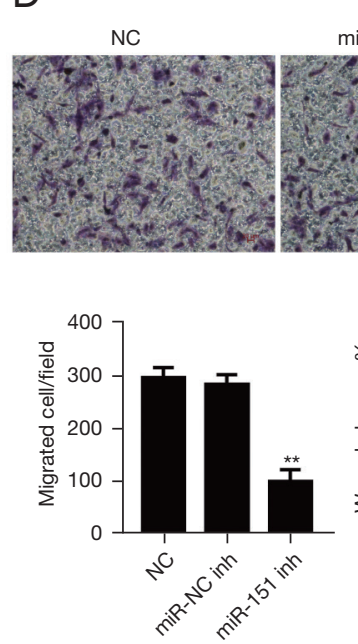

6

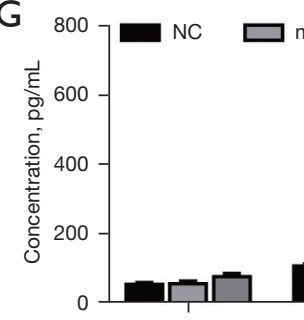

IL-2

I

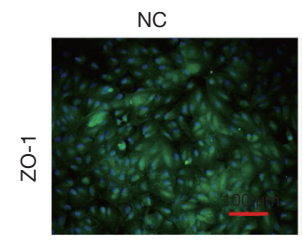

B

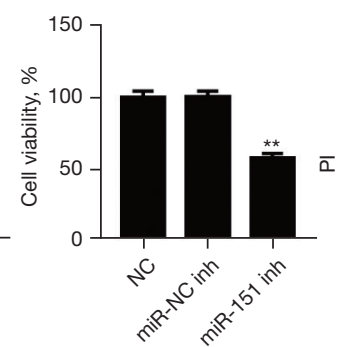

C
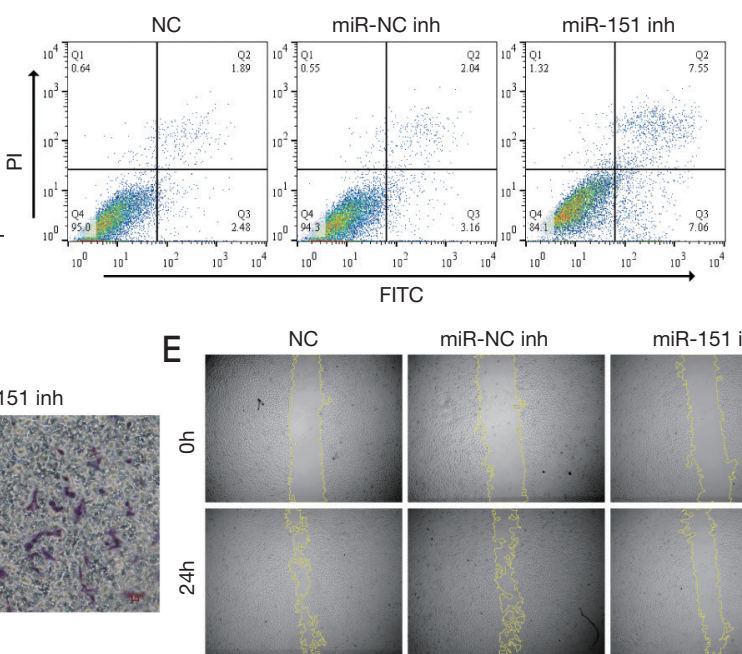

miR-NC inh miR-151 inh

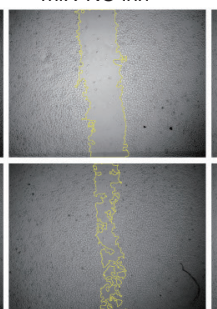

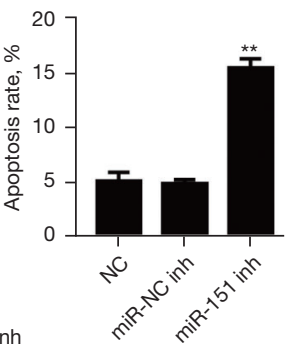

miR-NC inh

miR-151 inh
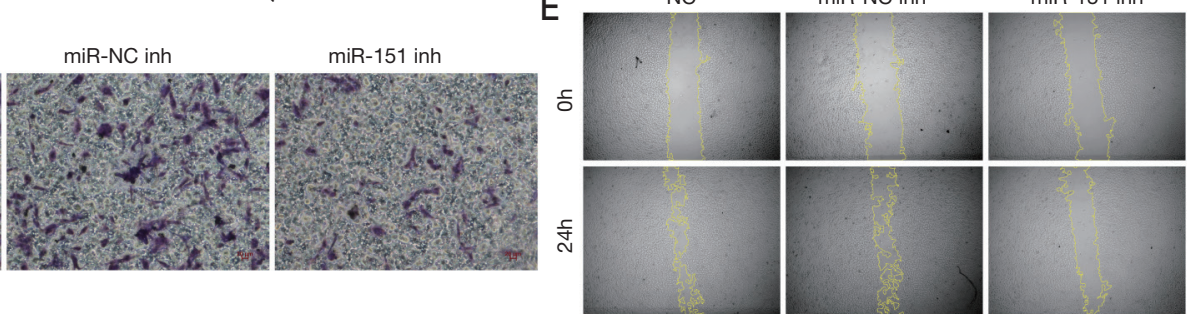

$\mathrm{F}$
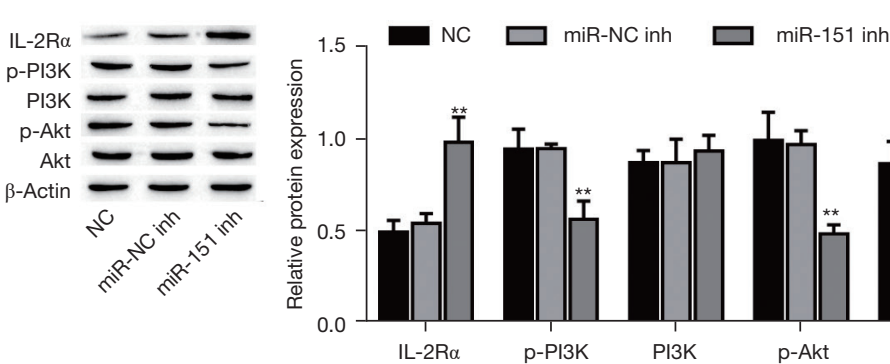

$\mathrm{H}$

P-PI3K $\quad$ PI3K

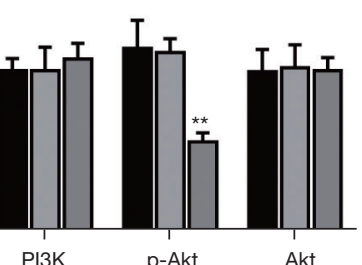
$\mathrm{p}-\mathrm{Akt} \quad \mathrm{Akt}$
$\mathrm{NC}$

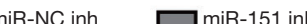

(1)
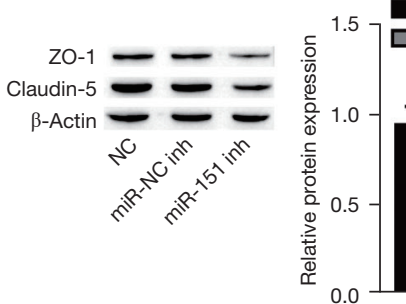

miR-151 inh

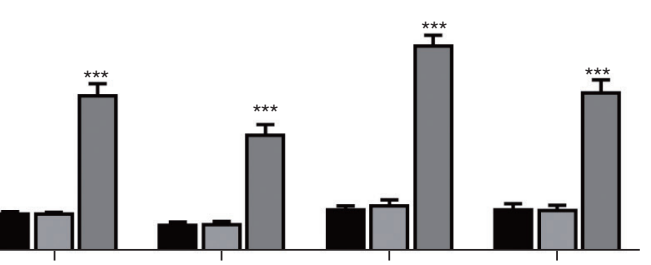

IL-1 $\beta$

IFN- $\gamma$

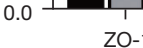

miR-NC inh

miR-151 inh

NC

miR-NC inh

$\mathrm{ZO}-1$
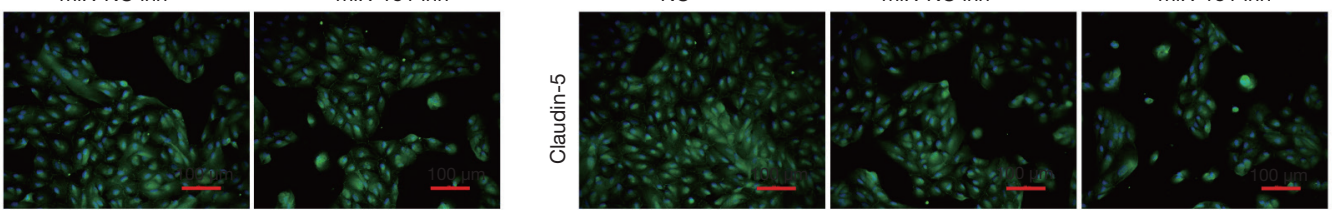

Figure 2 Requirement of miR-151-5p for proliferation and migration of B4G12 cells. (A) miR-151-5p expression measured by RT-qPCR $(\mathrm{n}=3)$. (B) Viability of B4G12 cells detected by CCK-8 assay (n=3). (C) Apoptosis of B4G12 cells examined using flow cytometry $(\mathrm{n}=3)$. (D) Migration of B4G12 cells were stained with $0.1 \%$ crystal violet for 15 min (magnification $\times 40$; scale bar: $20 \mu \mathrm{m}$; $\mathrm{n}=3$ ). (E) Migration of B4G12 cells were detected by wound-healing assays (magnification $\times 40 ; n=3$ ). (F) Expression level of protein examined by Western blot ( $\mathrm{n}=3$ ). (G) Levels of five inflammation factors evaluated by ELISA assay $(\mathrm{n}=3)$. (H) Expression level of protein examined by Western blot $(\mathrm{n}=3)$. (I) Immunofluorescence staining of ZO-1 or Claudin-5 in B4G12 cells (scale bar: $100 \mu \mathrm{m}$ ). ${ }^{* *}, \mathrm{P}<0.01$ compared with NC; ${ }^{* * *}, \mathrm{P}<0.001$ compared with NC. CCK, Cell Counting Kit; ELISA, enzyme-linked immunosorbent assay; inh, inhibitors; miR, microRNA; NC, negative control; RT-qPCR, real-time quantitative PCR; IFN, interferon; IL, interleukin; TNF, tumor necrosis factor. 

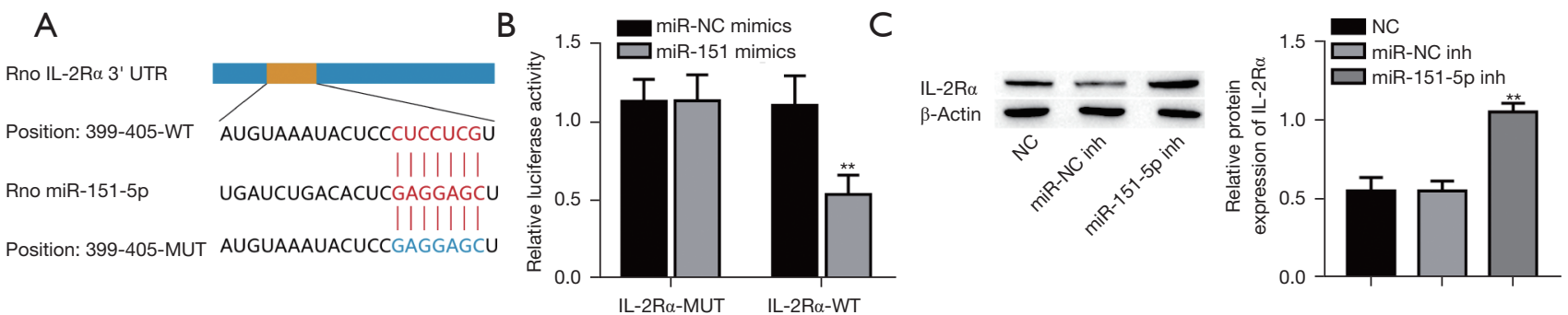

Figure $3 I L-2 R a$ targets miR-151-5p. (A) Schematic of the binding site of miR-151-5p and $I L-2 R a(n=3)$. (B) Dual-luciferase reporter assays prove miR-151-5p can target $I L-2 R a(\mathrm{n}=3)$. (C) Silencing miR-151-5p significantly increases the $I L-2 R a$ expression level (n=3). **, $\mathrm{P}<0.01$ compared with NC. inh, inhibitors; miR, microRNA; NC, negative control; MUT, mutant; WT, wild type.

immunofluorescence analysis showed that miR-151-5p knockdown significantly reduced ZO-1 and Claudin-5 in cell-cell boundaries and cytoplasm, respectively (Figure 2I). These data indicated that downregulation of miR-151-5p decreases the proliferation and migration of B4G12 cells and inhibits the PI3K/AKT signaling pathway.

\section{Effect of miR-151-5p on IL-2Ra}

To determine whether $I L-2 R a$ is the target of miR-151-5p, we identified that the 3'-UTR region of $I L-2 R a$ has only one highly conserved miR-151-5p binding site (Figure $3 A$ ). Overexpression of miR-151-5p significantly decreased the luciferase activity of the $I L-2 R a-W T$ reporter vector, whereas $I L-2 R a-M U T$ reporter and miR-151-5p mimic cotransfection failed to affect luciferase activity in 293 $\mathrm{T}$ cells (Figure 3B), and downregulation of miR-151-5p inhibited IL-2Ra expression (Figure 3C). Altogether, these results proved that miR-151-5p directly targets $I L-2 R a$.

\section{Mechanism of the effect of IL-2Ra overexpression on B4G12 cell proliferation and migration}

To explore the functions of IL-2Ra in B4G12 cell proliferation, migration, and the $\mathrm{PI} 3 \mathrm{~K} / \mathrm{AKT}$ signaling pathway, we overexpressed IL-2Ra by transfected $I L-2 R a$ overexpression plasmid. The expression of IL-2Ra was effectively increased, but IGF-1, a PI3K/AKT signaling pathway activator, did not affect IL-2 Ra expression (Figure 4A). Importantly, IL-2 Ra overexpression dramatically inhibited p-PI3K and p-AKT expression, but IGF-1 abolished the inhibiting effect of IL-2Ra overexpression (Figure 4A). CCK-8 assay suggested that upregulation of IL-2 $\mathrm{Ra}$ inhibited cell activity that was recovered with IGF-1 (Figure 4B). The apoptosis of B4G12 cells was significantly increased after overexpression of IL-2Ra, but IGF-1 abolished the promotional effect of overexpressed IL-2Ra (Figure 4C). By contrast, IL-2Ra overexpression remarkably reduced B4G12 cell migration, which was recovered with IGF-1 treatment (Figure 4D,4E). Importantly, overexpression of IL-2Ra dramatically reduced ZO-1 and Claudin-5 protein expressions, which were also recovered with IGF-1 treatment (Figure 4F). Furthermore, immunofluorescence analysis showed that IL-2Ra overexpression significantly reduced ZO-1 and Claudin-5 in the cell-cell boundaries and cytoplasm, respectively, but IGF-1 abolished the inhibiting effect of the overexpression of IL-2Ra (Figure 4G). Additionally, IL-2Ra overexpression significantly increased the levels of inflammatory cytokines IL-6, IL-1 $\beta$, TNF- $\alpha$, and IFN- $\gamma$, which were reduced with IGF-1 treatment (Figure 4H). Overall, these data indicated that IL-2Ra plays a critical role in the proliferation and migration of B4G12 cells by inhibiting the PI3K/AKT signaling pathway.

\section{Mechanism of the effect of downregulation of miR-151-5p on B4G12 cells proliferation and migration}

Furthermore, the effect of the miR-151-5p/IL-2Ra/PI3K/ $\mathrm{AKT}$ axis on the proliferation and migration of B4G12 cells was explored. Firstly, the expression of IL-2Ra was detected using Western blotting, and the results showed that downregulation of miR-151-5p increased the level of IL-2Ra, which was reversed with interference of $I L-2 R a$ (Figure $5 A$ ). Next, we investigated whether miR-151-5p/ IL-2Ra/PI3K/AKT regulated the apoptosis, proliferation and migration of B4G12 cells. We found that miR-151-5p downregulation significantly increased B4G12 cell apoptosis but was reversed with interference of $I L-2 R a$ (Figure $5 B$ ). By contrast, downregulation of miR-151-5p remarkably 

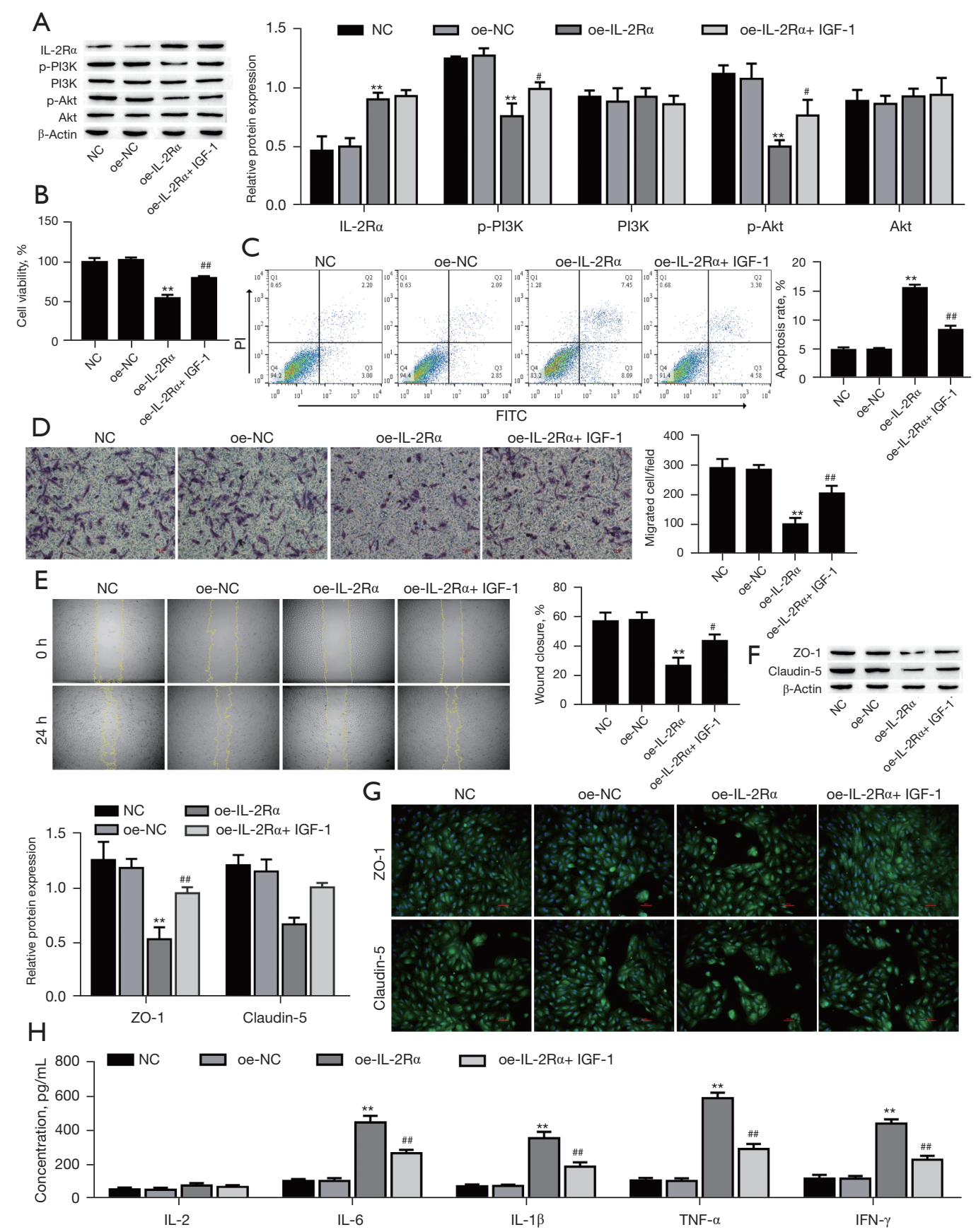

Figure 4 IL-2Ra overexpression reduces B4G12 cell proliferation and migration by inhibiting the PI3K/AKT signaling pathway. (A) Expression level of protein examined by Western blot (n=3). (B) Viability of B4G12 cells detected by CCK-8 assay ( $\mathrm{n}=3$ ). (C) Apoptosis of B4G12 cells examined using flow cytometry (n=3). (D) Migration of B4G12 cells were stained with $0.1 \%$ crystal violet for 15 min (magnification $\times 40$; scale bar: $20 \mu \mathrm{m} ; \mathrm{n}=3$ ). (E) Migration of B4G12 cells were detected by wound-healing assays (magnification $\times 40 ; n=3$ ). (F,G) ZO-1 and Claudin-5 expressions determined by Western blot and immunofluorescence assays, immunofluorescence staining of ZO-1 and or Claudin-5 (scale bar: $100 \mu \mathrm{m})$. (H) Inflammation factor levels evaluated by ELISA assay $(\mathrm{n}=3) .{ }^{* *}, \mathrm{P}<0.01$ compared with $\mathrm{NC}$; ${ }^{*}$, $\mathrm{P}<0.05$ compared with oe-IL-2Ra; and ${ }^{\# \#}, \mathrm{P}<0.01$ compared with oe-IL-2Ra. ELISA, enzyme-linked immunosorbent assay; IL, interleukin; IFN, interferon; TNF, tumor necrosis factor; inh, inhibitors; miR, microRNA; NC, negative control; oe, overexpression; RT-qPCR, realtime quantitative PCR. 


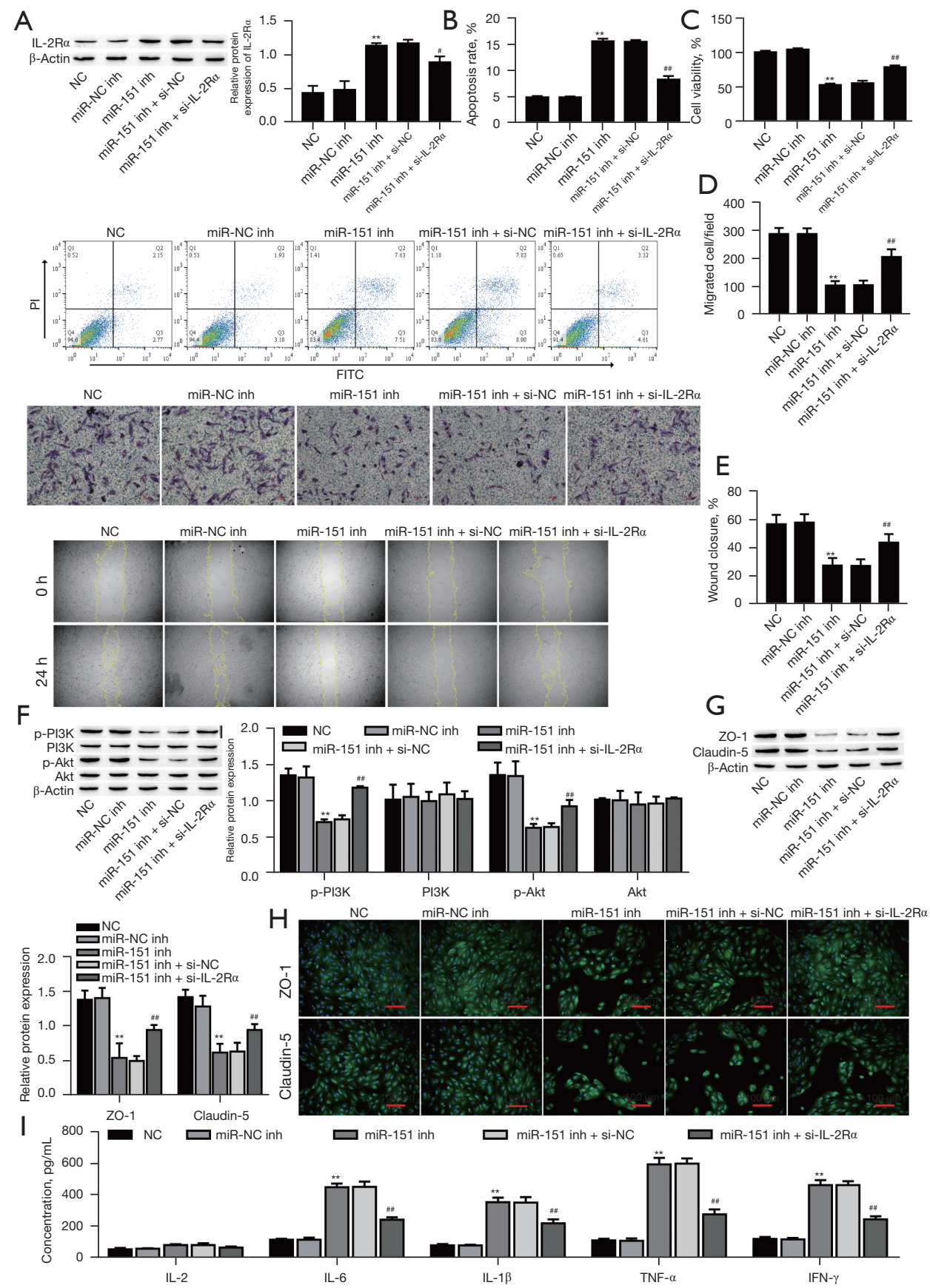

Figure 5 Downregulation of miR-151-5p reduces B4G12 cell proliferation and migration via the PI3K/AKT pathway by promoting IL2Ra. (A) IL-2Ra protein expression examined using Western blot ( $\mathrm{n}=3$ ). (B) Apoptosis of B4G12 cells examined by flow cytometry ( $\mathrm{n}=3$ ). (C) Viability of B4G12 cells examined using CCK-8 assay (n=3). (D) Migration of B4G12 cells were stained with $0.1 \%$ crystal violet for 15 min (magnification $\times 40$; scale bar: $20 \mu \mathrm{m} ; \mathrm{n}=3$ ). (E) Migration of B4G12 cells were detected by wound-healing assays (magnification $\times 40$; $\mathrm{n}=3$ ). $(\mathrm{F}, \mathrm{G})$ Protein levels determined by Western blot $(\mathrm{n}=3)$. (H) Immunofluorescence staining of ZO-1 or Claudin-5 in B4G12 cells (scale bar: $100 \mu \mathrm{m})$. (I) Levels of inflammation factors evaluated by ELISA assay (n=3). **, $\mathrm{P}<0.01$ compared with $\mathrm{NC}$; *, $\mathrm{P}<0.05$ compared with miR151-5p inhibitors; and ${ }^{\# \#}, \mathrm{P}<0.01$ compared with miR-151-5p inhibitors. CCK, Cell Counting Kit; ELISA, enzyme-linked immunosorbent assay; IFN, interferon; IL, interleukin; TNF, tumor necrosis factor; inh, inhibitors; miR, microRNA; NC, negative control; RT-qPCR, realtime quantitative PCR; si, small interfering. 
decreased the proliferation and migration of B4G12 cells, which was reversed with interference of $I L-2 R a$ (Figure 5C-5E). Notably, miR-151-5p downregulation significantly reduced the expression of p-PI3K and p-AKT, which was reversed by downregulation of IL$2 \mathrm{Ra}$ (Figure $5 \mathrm{~F}$ ). Importantly, downregulation of miR151-5p dramatically reduced ZO-1 and Claudin-5 protein expressions, which were recovered with IL$2 \mathrm{Ra}$ overexpression (Figure $5 G$ ). Furthermore, immunofluorescence analysis showed that miR-151-5p downregulation significantly reduced ZO-1 and Claudin-5 in the cell-cell boundaries and cytoplasm, respectively, but downregulation of IL-2Ra abolished the inhibiting effect of miR-151-5p downregulation (Figure 5H). Additionally, miR-151-5p silencing significantly increased the levels of inflammatory cytokines IL- 6 , IL- $1 \beta$, TNF- $\alpha$, and IFN- $\gamma$, which were reduced with IGF-1 treatment (Figure $5 I$ ). Collectively, the results revealed that miR-151-5p downregulation exerts inhibitory effect on B4G12 cell proliferation and migration via inhibition of PI3K/AKT through upregulation of IL-2Ra.

\section{Mechanism of effect of upregulation of miR-151-5p on CGR}

Figure $6 \mathrm{~A}$ shows color photographs at 14 days after CT. In the CGR group, we observed that opacity and edema were significantly greater, and new vessels extended to the graft compared with the Sham group. The agomiR-151-5p mimics and agomiR-151-5p mimics+oe-IL-2Ra groups of grafts had notable effects, and new vessels were decreased in number. Compared with the Sham group, a large number of inflammatory cells and obvious edema, and lower CEC numbers were observed in the corneal stroma of the CGR group (Figure 6B). In the agomiR-151-5p mimics group, the corneal stroma exhibited fewer inflammatory cells, less edema, and higher CECs number compared with the CGR group, but these effects were reversed by overexpression of IL-2Ra. Kaplan-Meier survival curve analysis showed the agomiR-151-5p mimics+oe-IL-2Ra and agomiR-151-5p mimics groups had reduced graft rejection rates compared with the CGR group (Figure 6C). We found that graft rejection started the earliest (day 7) in the CGR group, then the agomiR-151-5p mimics + oe-IL-2Ra group at day 8 , and the agomiR-151-5p mimics group (day 9) was the last. AgomiR-151-5p and AgomiR-151-5p mimics+oe-IL$2 \mathrm{Ra}$ remarkably prolonged the graft survival time (median survival time, 18 and 14 days, respectively) compared with the CGR group (median survival time, 10 days). These data suggested that the miR-151-5p/IL-2Ra axis regulates the survival of the CT. Next, the levels of inflammatory cytokines IL-2, IL- 6 , IL- $1 \beta$, TNF- $\alpha$, and IFN- $\gamma$ were determined using ELISA. As shown in Figure 6D, CGR increased the levels of inflammatory cytokines levels but this was reversed with AgomiR-151-5p mimics, and inflammatory cytokine levels were finally recovered with IL-2Ra overexpression. Because the balance of Th17/Treg is important for CGR, to further detect immune rejection the Th17 and Treg populations in the PBMCs of the rats were measured by flow cytometry. Compared with the Sham group, the CGR group showed an increased Th17/ Treg ratio, which was recovered with agomiR-151-5p mimics treatment; the Th17/Treg ratio was finally abolished with overexpression of IL-2Ra (Figure 6E-6G). These data suggested that the miR-151-5p/L-2Ra axis alleviates CGR in rats.

We further measured miR-151-5p and IL-2Ra expressions in corneas by RT-qPCR and Western blot, respectively. We noticed that CGR significantly downregulated miR-151-5p expression in the CT rats (Figure $7 A$ ), but it remarkably enhanced the IL-2Ra level (Figure 7B). Inversely, agomiR-151-5p mimics treatment effectively upregulated the expression of miR-151-5p in the CGR rats (Figure $7 A$ ), but remarkably reduced the IL-2Ra level (Figure 7B). Notably, the level of phosphorylated PI3K and AKT were lowly expressed in the CGR, which was reversed with upregulation of miR-151-5p, and the p-PI3K and $\mathrm{p}-\mathrm{AKT}$ levels were finally abolished by overexpression of IL-2Ra (Figure 7C). However, the expressions of PI3K and AKT were not significantly different among the groups. Additionally, the expressions of ZO-1 and Claudin-5 were remarkably decreased, but were reversed with upregulation of miR-151-5p, and finally downregulated with overexpression of IL-2Ra (Figure 7D).

All together, our data showed that upregulation of miR151-5p activated the PI3K/AKT signaling pathway through downregulating IL-2Ra, thus reducing the incidence of CGR and improving the survival of CT in rats.

\section{Discussion}

CT is the only treatment for corneal blindness, but the immune rejection-induced graft failure is a major hurdle $(2,36)$. Regulation of the Th17/Treg ratio to prevent and treat CGR is still an ongoing and important issue in clinical research $(37,38)$. However, the details of Th17/Treg 
A Sham CGR miR-151 mim

miR-151 mim + oe-IL-2R $\alpha$
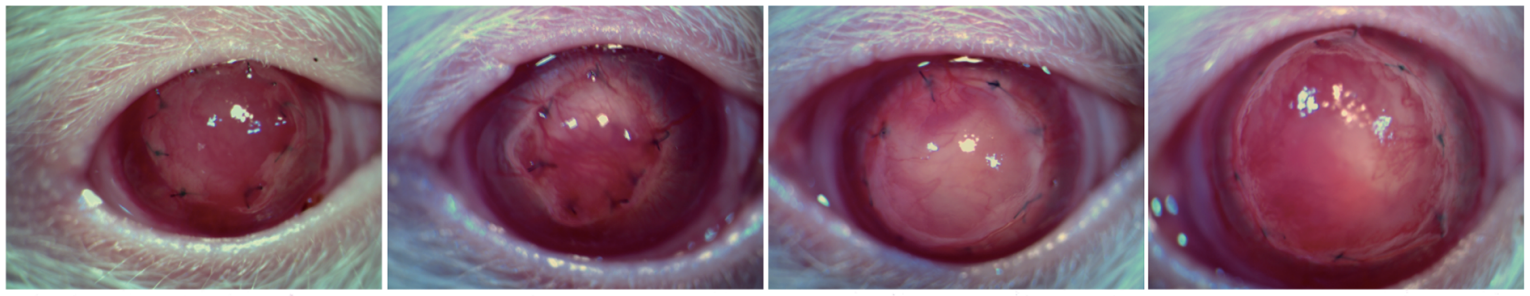

B
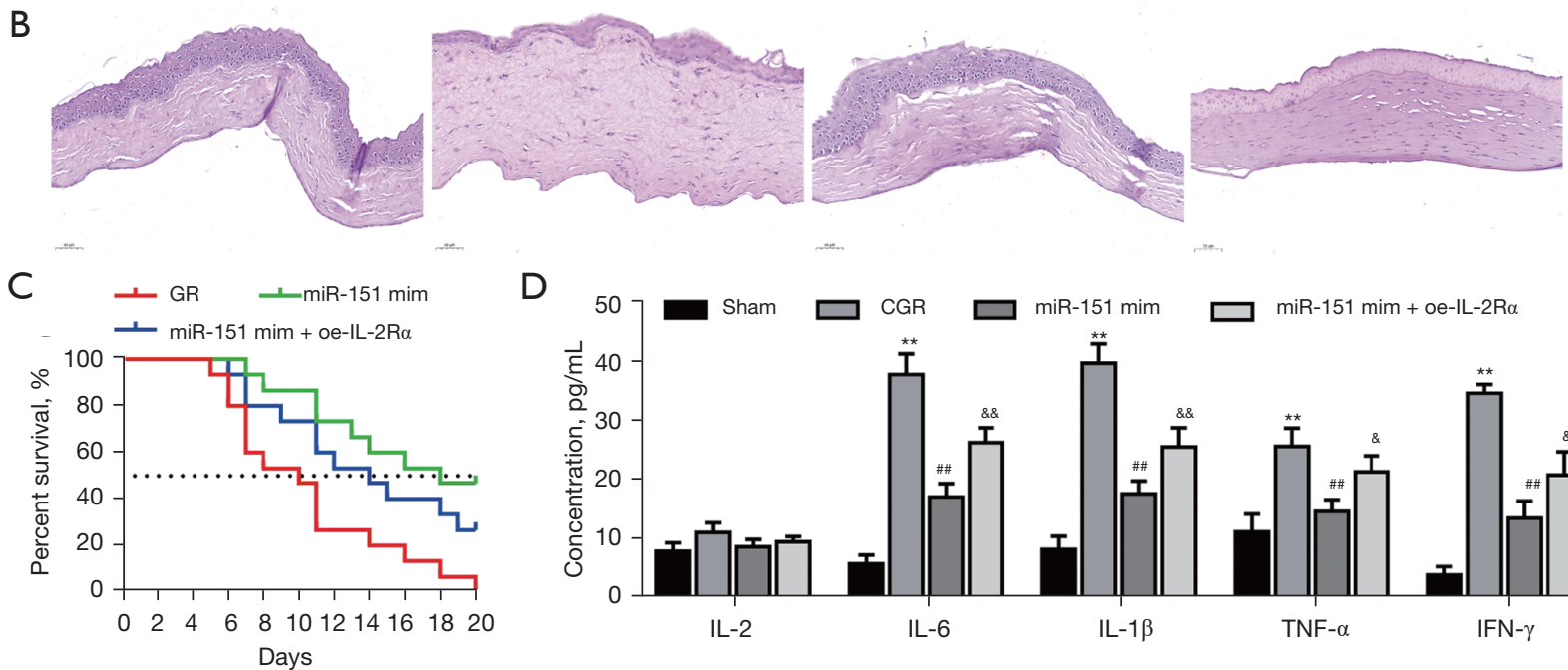

D
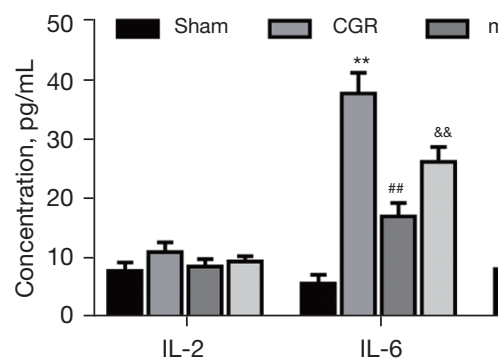

IL-6

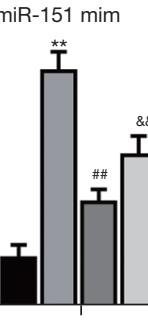

$\square \mathrm{miR}-151 \mathrm{mim}+\mathrm{oe}-\mathrm{IL}-2 \mathrm{R} \alpha$
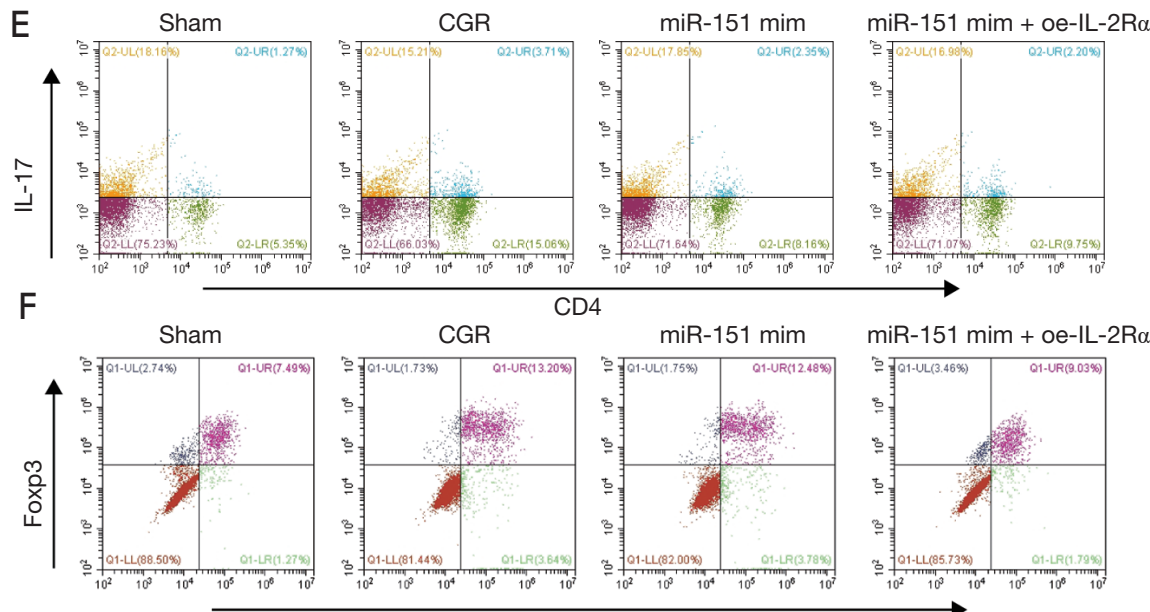

miR-151 mim + oe-IL-2R $\alpha$
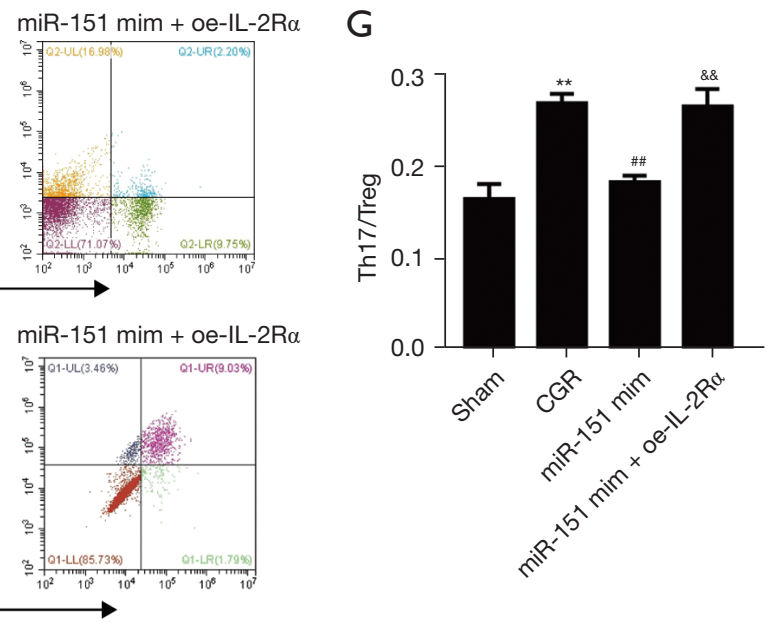

Figure 6 Downregulation of miR-151-5p alleviates CGR. (A) Color photographs obtained during examination of rejected and surviving grafts. (B) Representative images of hematoxylin-eosin staining at day 14 (scale bar: $50 \mu \mathrm{m}$ ). (C) Kaplan-Meier survival curves show miR151-5p downregulation significantly increased graft survival and decreased graft rejection ( $\mathrm{n}=15$ ). (D) Concentration of inflammation factors in aqueous humor by ELISA ( $\mathrm{n}=6)$. (E,F) Proportions of Th17 (CD4+IL-17+ cells) and Treg cells (CD25+Foxp3+ cells) in cultured splenocytes subjected to different treatments $(n=6)$. (G) Ratio of Th17/Treg cells in cultured splenocytes subjected to different treatments ( $\mathrm{n}=6)$. **, $\mathrm{P}<0.01$ compared with Sham; ${ }^{\# \#}, \mathrm{P}<0.01$ compared with $\mathrm{CGR} ;{ }^{*}, \mathrm{P}<0.05$ compared with miR-151-5p mimics; and ${ }^{\& \&}, \mathrm{P}<0.01$ compared with miR-151-5p mimics. CGR, corneal graft rejection; mim, mimics; miR: microRNA; NC, negative control; oe, overexpression lentiviral vector; RT-qPCR, real-time quantitative PCR; IFN, interferon; IL, interleukin; TNF, tumor necrosis factor; Treg, regulatory T cell; Th17, T helper cells. 
A

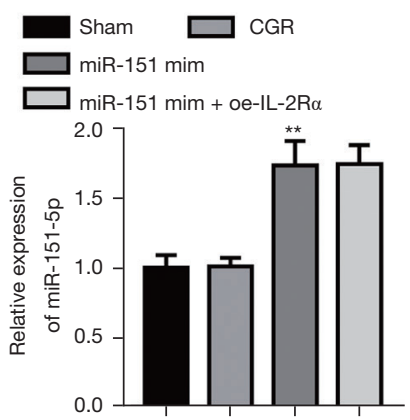

C

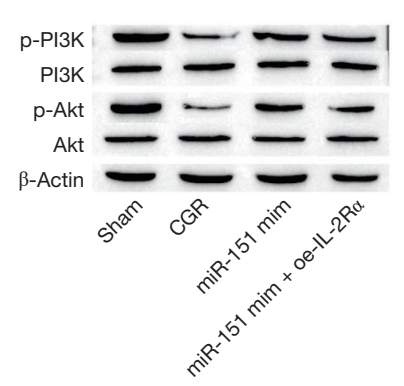

D

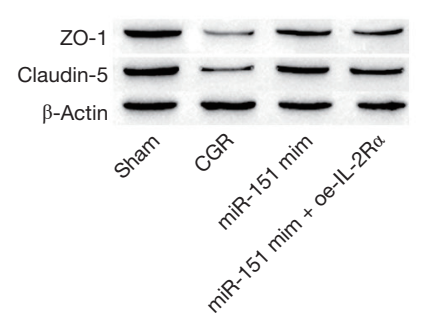

B

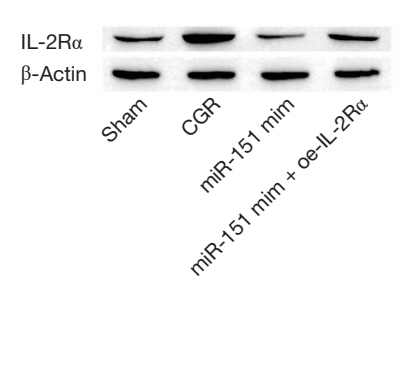

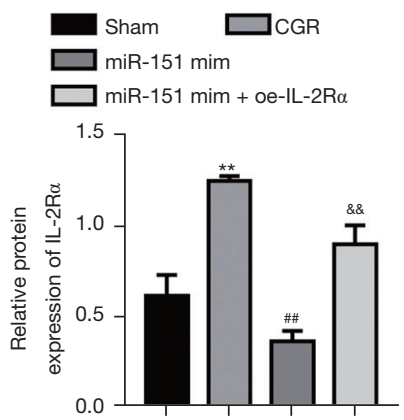
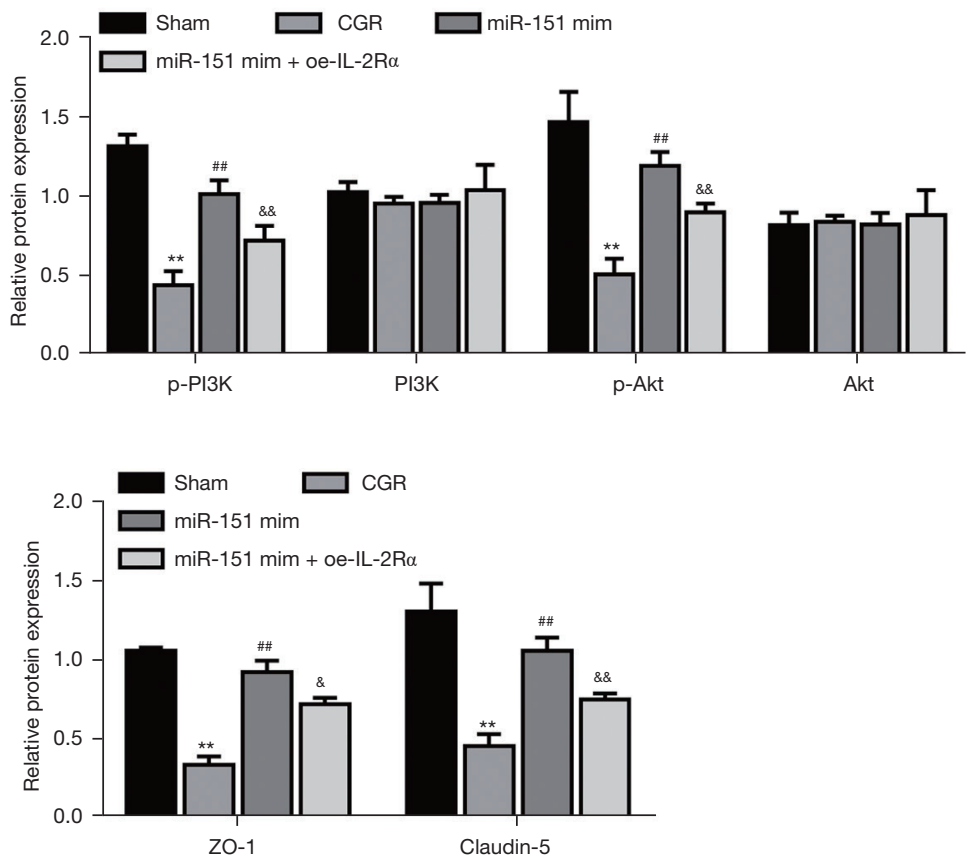

Figure 7 Downregulation of miR-151-5p activation of PI3K/AKT signaling pathway by inhibiting IL-2Ra in rats. (A) miR-151-5p expression determined using RT-qPCR ( $\mathrm{n}=6$ ). (B-D) Protein levels determined using Western blot $(\mathrm{n}=6)$. **, $\mathrm{P}<0.01$ compared with Sham; \#\#, $\mathrm{P}<0.01$ compared with CGR; ${ }^{\circ}, \mathrm{P}<0.05$ compared with miR-151-5p mimics; and ${ }^{\& \&}, \mathrm{P}<0.01$ compared with miR-151-5p mimics. CGR, corneal graft rejection; mim, mimics; miR, microRNA; NC, negative control; oe, overexpression lentiviral vector; RT-qPCR, real-time quantitative PCR.

disorder in CGR remain largely unknown. In this study, we established a rat CGR model and through transcriptome microarray analysis, we identified 453 DEMs in graftrejection corneas. Among these DEMs, we defined the miR-151-5p/IL-2Ra axis as playing a critical role in the regulation of Th17/Treg balance and CEC proliferation and migration.

The miRNAs are reported to play important roles in cellular processes $(39,40)$, exerting their activity via different mechanisms, including modulation of gene expression, post-transcriptional regulation and targeting mRNAs and inducing their translational repression or deadenylation and degradation (40). Notably, accumulating evidence shows that miRNAs modulate the Th17/Treg ratio and also cell proliferation and migration (41-45). Here we found there was reduced miR-151-5p expression and an elevated Th17/Treg ratio in CGR rats, and that agomiR151-5p treatment decreased the Th17/Treg ratio. miR-151$5 \mathrm{p}$ downregulation reduced B4G12 cell proliferation and migration in vitro. The PI3K/AKT signaling pathway plays pivotal roles in balancing the Th17/Treg ratio and in cell proliferation and migration $(14,15,18)$. Interestingly, both 
CGR and downregulation of miR-151-5p inhibited the PI3K/AKT signaling pathway. Aberrant activation and/or inhibition of the PI3K/AKT signaling pathway is implicated in corneal and other tissue transplantation failures $(14,16)$. Here, we showed that activation of the PI3K/AKT signaling pathway increased B4G12 cell proliferation and migration, and alleviated immune rejection-induced CEC loss by downregulating miR-151-5p, suggesting that the miR-151$5 \mathrm{p}$-medicated PI3K/AKT signaling pathway is critical for immune rejection-induced graft failure.

In this study, we found that IL-2Ra is a target of miR151-5p; overexpression of IL-2Ra reduced B4G12 cell proliferation and migration, and $I L-2 R a$ knockdown alleviated the decrease in cell proliferation and migration by miR-151-5p downregulation. It is well known that IL-2R is mainly expressed in the T cells that modulate tolerance and immunity functions $(46,47)$. Interestingly, previous studies have shown that IL-2R is also expressed in non-T cells, including cervical cancer cells, ECs, vascular smooth muscle cells, and other cells (48-52). IL$2 \mathrm{R}$ upregulation causes inflammation, but inhibition or activity knockdown of IL-2R attenuates inflammationinduced cell injury, suggesting that IL-2R play an important role in the regulation of cell proliferation and migration. IL-2R has been suggested as a marker of acute rejection after organ transplantation, because it is significantly higher in rejection (53). Both IL-2 and IL-2R signaling play an important role in regulating both tolerance and immunity (48). Enhanced allograft survival via blockade of IL-2R $(54,55)$ may provide a new perspective for the treatment of allogeneic responses in patients after transplantation. IL-2Ra was regulated by miR-151-5p in CGR to modulate the PI3K/AKT signaling pathway, which primes the immune rejection of CT, suggesting that IL$2 \mathrm{Ra}$ is a suppressor of the PI3K/AKT signaling pathway in vivo in response to CGR. Human PMSC transplantation changes the ratio of Th17/Treg cells by the PI3K/Akt signaling pathway in premature ovarian failure (56), activation of which promotes CEC proliferation (17). A recent study reported that carbamylated erythropoietin regulates immune responses and promotes long-term kidney allograft survival through activation of PI3K/AKT signaling (14). In our study, activation of the PI3K/AKT signaling pathway increased B4G12 cell proliferation and migration. However, PI3K/AKT signaling was inhibited after CGR but was recovered with miR-151-5p mimics treatment. These observations indicated that miR-151-5p mediated IL-2Ra expression, which inhibited the PI3K/
AKT signaling pathway cascade to immune rejection and CEC loss. Thus, targeting the miR-151-5p/IL-2Ra axis is a novel strategy for clinical intervention of CGR.

The corneal endothelium is a single layer of hexagonal cells that maintain corneal transparency and thickness through barrier and pump functions (57). Higher expression of tight junction protein is maintained at cell junctions (58). In this study, we demonstrated that miR151-5p downregulation and CGR reduced tight junction protein expression, which were respectively reversed with overexpression of IL-2Ra and miR-151-5p. Previous studies have demonstrated that activation of the PI3K/ AKT signaling pathway increases tight junction protein expression $(59,60)$. Our data support the idea that miR1269/IL-2Ra axis-mediated PI3K/AKT signaling pathway activation in CGR plays an important role in the regulation of corneal endothelium function.

In conclusion, miR-151-5p downregulation inhibited CEC proliferation and migration and promoted immune rejection through inhibition of the PI3K/AKT signaling pathway by upregulating IL-2Ra in rats. Our study provides experimental evidence that supports the miR-151$5 \mathrm{p} / \mathrm{IL}-2 \mathrm{Ra}$ axis as a novel strategy for clinical intervention of CGR.

\section{Acknowledgments}

Funding: This work was supported by Associated Project of Yunnan Province Science \& Technology Department and Kunming Medical University Basic Research for Application [2018FE001-(010)].

\section{Footnotes}

Reporting Checklist: The authors have completed the ARRIVE reporting checklist. Available at https://dx.doi. org/10.21037/atm-21-2054

Data Sharing Statement: Available at https://dx.doi. org/10.21037/atm-21-2054

Conflicts of Interest: All authors have completed the ICMJE uniform disclosure form (available at https://dx.doi. org/10.21037/atm-21-2054). The authors have no conflicts of interest to declare.

Ethical Statement: The authors are accountable for all aspects of the work in ensuring that questions related 
to the accuracy or integrity of any part of the work are appropriately investigated and resolved. Experiments were performed under a project license (No. YLS202018) granted by the Animal Experimental Ethical Inspection of the Affiliated Calmette Hospital of Kunming Medical University, in compliance with the management requirements of the Animal Management Association of the Affiliated Calmette Hospital of Kunming Medical University for the care and use of animals.

Open Access Statement: This is an Open Access article distributed in accordance with the Creative Commons Attribution-NonCommercial-NoDerivs 4.0 International License (CC BY-NC-ND 4.0), which permits the noncommercial replication and distribution of the article with the strict proviso that no changes or edits are made and the original work is properly cited (including links to both the formal publication through the relevant DOI and the license). See: https://creativecommons.org/licenses/by-nc-nd/4.0/.

\section{References}

1. Flaxman SR, Bourne RRA, Resnikoff S, et al. Global causes of blindness and distance vision impairment 19902020: a systematic review and meta-analysis. Lancet Glob Health 2017;5:e1221-e1234.

2. Lechler RI, Sykes M, Thomson AW, et al. Organ transplantation--how much of the promise has been realized? Nat Med 2005;11:605-13.

3. Reorganized text. JAMA Otolaryngol Head Neck Surg 2015;141:428.

4. Williams KA, Lowe M, Bartlett C, et al. Risk factors for human corneal graft failure within the Australian corneal graft registry. Transplantation 2008;86:1720-4.

5. Amouzegar A, Chauhan S, Dana R. Alloimmunity and tolerance in corneal transplantation. J Immunol 2016;196:3983-91.

6. Hashemian MN, Latifi G, Ghaffari R, et al. Topical tacrolimus as adjuvant therapy to corticosteroids in acute endothelial graft rejection after penetrating keratoplasty: A randomized controlled trial. Cornea 2018;37:307-12 .

7. Ross AH, Jones MN, Nguyen DQ, et al. Long-term topical steroid treatment after penetrating keratoplasty in patients with pseudophakic bullous keratopathy. Ophthalmology 2009;116:2369-72.

8. Khodadoust AA, Silverstein AM. Transplantation and rejection of individual cell layers of the cornea. Invest Ophthalmol 1969;8:180-95.
9. Boisgérault F, Liu Y, Anosova N, et al. Role of CD4+ and CD8+ T cells in allorecognition: lessons from corneal transplantation. J Immunol 2001;167:1891-9.

10. Claerhout I, Beele H, Kestelyn P. Graft failure: I. Endothelial cell loss. Int Ophthalmol 2008;28:165-73.

11. Patel SV, Hodge DO, Bourne WM. Corneal endothelium and postoperative outcomes 15 years after penetrating keratoplasty. Am J Ophthalmol 2005;139:311-9.

12. Wang X, Wang $\mathrm{W}, \mathrm{Xu} \mathrm{J}$, et al. All-trans retinoid acid promotes allogeneic corneal graft survival in mice by regulating Treg-Th17 balance in the presence of TGF- . BMC Immunol 2015;16:17.

13. Coco G, Foulsham W, Nakao T, et al. Regulatory T cells promote corneal endothelial cell survival following transplantation via interleukin-10. Am J Transplant 2020;20:389-98.

14. Na N, Zhao D, Zhang J, et al. Carbamylated erythropoietin regulates immune responses and promotes long-term kidney allograft survival through activation of PI3K/AKT signaling. Signal Transduct Target Ther 2020;5:194.

15. Fang J, Hu F, Ke D, et al. N,N-dimethylsphingosine attenuates myocardial ischemia-reperfusion injury by recruiting regulatory $\mathrm{T}$ cells through $\mathrm{PI} 3 \mathrm{~K} / \mathrm{Akt}$ pathway in mice. Basic Res Cardiol 2016;111:32.

16. Lu X, Wu J, Ma M, et al. An integrated deep sequencing analysis of microRNAs in transplanted corneas. Mol Immunol 2018;101:429-39.

17. Sabater AL, Andreu EJ, García-Guzmán M, et al. Combined PI3K/Akt and Smad 2 activation promotes corneal endothelial cell proliferation. Invest Ophthalmol Vis Sci 2017;58:745-54.

18. Couture C, Desjardins P, Zaniolo K, et al. Enhanced wound healing of tissue-engineered human corneas through altered phosphorylation of the CREB and AKT signal transduction pathways. Acta Biomater 2018;73:31225.

19. Huang JL, Cao SW, Ou QS, et al. The long non-coding RNA PTTG3P promotes cell growth and metastasis via up-regulating PTTG1 and activating PI3K/AKT signaling in hepatocellular carcinoma. Mol Cancer 2018;17:93.

20. Gürsel DB, Connell-Albert YS, Tuskan RG, et al. Control of proliferation in astrocytoma cells by the receptor tyrosine kinase/PI3K/AKT signaling axis and the use of PI-103 and TCN as potential anti-astrocytoma therapies. Neuro Oncol 2011;13:610-21.

21. Eulalio A, Huntzinger E, Izaurralde E. Getting to the root of miRNA-mediated gene silencing. Cell 2008;132:9-14. 
22. Shaked A, Chang B, Barnes M, et al. An ectopically expressed serum miRNA signature is prognostic, diagnostic, and biologically related to liver allograft rejection. Hepatology 2017;65:269-80.

23. Bijkerk R, Florijn B, Khairoun M, et al. Acute rejection after kidney transplantation associates with circulating microRNAs and vascular injury. Transplant Direct 2017;3:e174.

24. Millán O, Budde K, Sommerer C, et al. Urinary miR155-5p and CXCL10 as prognostic and predictive biomarkers of rejection, graft outcome and treatment response in kidney transplantation. Br J Clin Pharmacol 2017;83:2636-50.

25. Millán O, Ruiz P, Orts L, et al. Monitoring of miR-181a$5 \mathrm{p}$ and miR-155-5p Plasmatic Expression as Prognostic Biomarkers for Acute and Subclinical Rejection in de novo Adult Liver Transplant Recipients. Front Immunol 2019;10:873.

26. Wang T, Li F, Geng W, et al. MicroRNA-122 ameliorates corneal allograft rejection through the downregulation of its target CPEB1. Cell Death Discov 2017;3:17021.

27. Liu Z, Lin H, Huang C, et al. Development and effects of FTY720 ophthalmic solution on corneal allograft survival. Sci Rep 2015;5:16468.

28. Larkin DF, Calder VL, Lightman SL. Identification and characterization of cells infiltrating the graft and aqueous humour in rat corneal allograft rejection. Clin Exp Immunol 1997;107:381-91.

29. Livak KJ, Schmittgen TD. Analysis of relative gene expression data using real-time quantitative PCR and the 2(-Delta Delta C(T)) Method. Methods 2001;25:402-8.

30. Qin Q, Luo D, Shi Y, et al. CD25 siRNA induces Treg/ Th1 cytokine expression in rat corneal transplantation models. Exp Eye Res 2016;151:134-41.

31. Gaffen SL. Signaling domains of the interleukin 2 receptor. Cytokine 2001;14:63-77.

32. Niu X, Deng S, Li S, et al. Therapeutic effect of ergotope peptides on CIA by down-regulation of inflammatory and Th1/Th17 responses and induction of regulatory $\mathrm{T}$ cells. Mol Med 2016;22:608-20.

33. Niemeyer G, Koch M, Light S, et al. Long-term safety, tolerability and efficacy of daclizumab (Zenapax) in a two-dose regimen in liver transplant recipients. Am J Transplant 2002;2:454-60.

34. ter Meulen CG, Göertz JH, Klasen IS, et al. Decreased renal excretion of soluble interleukin-2 receptor alpha after treatment with daclizumab. Kidney Int 2003;64:697-703.

35. Yan H, Wang S, Yu H, et al. Molecular pathways and functional analysis of miRNA expression associated with paclitaxel-induced apoptosis in hepatocellular carcinoma cells. Pharmacology 2013;92:167-74.

36. Wang H, Zhao Q, Luo D, et al. Resolvin E1 inhibits corneal allograft rejection in high-risk corneal transplantation. Invest Ophthalmol Vis Sci 2018;59:3911-9.

37. Ye Q, Zhang M, Wang Y, et al. Sirtinol regulates the balance of Th17/Treg to prevent allograft rejection. Cell Biosci 2017;7:55.

38. Wu XS, Lu XL, Wu J, et al. Tocilizumab promotes corneal allograft survival in rats by modulating Treg-Th17 balance. Int J Ophthalmol 2019;12:1823-31.

39. Calin GA, Croce CM. MicroRNA signatures in human cancers. Nat rev Cancer 2006;6:857-66.

40. Krol J, Loedige I, Filipowicz W. The widespread regulation of microRNA biogenesis, function and decay. Nat rev Genet 2010;11:597-610.

41. Zheng X, Dong L, Wang K, et al. MiR-21 participates in the PD-1/PD-L1 pathway-mediated imbalance of Th17/ Treg cells in patients after gastric cancer resection. Ann Surg Oncol 2019;26:884-93.

42. Qu X, Han J, Zhang Y, et al. MiR-384 regulates the Th17/Treg ratio during experimental autoimmune encephalomyelitis pathogenesis. Front Cell Neurosci 2017;11:88.

43. Pang B, Zhen Y, Hu C, et al. Myeloid-derived suppressor cells shift Th17/Treg ratio and promote systemic lupus erythematosus progression through arginase-1/miR-3225p/TGF- $\beta$ pathway. Clin Sci (Lond) 2020;134:2209-22.

44. Gu Y, Liu S, Zhang X, et al. Oncogenic miR-19a and miR19b co-regulate tumor suppressor MTUS1 to promote cell proliferation and migration in lung cancer. Protein Cell 2017;8:455-66.

45. Zhu K, Liu L, Zhang J, et al. MiR-29b suppresses the proliferation and migration of osteosarcoma cells by targeting CDK6. Protein Cell 2016;7:434-44.

46. Malek TR, Castro I. Interleukin-2 receptor signaling: at the interface between tolerance and immunity. Immunity 2010;33:153-65.

47. Toomer KH, Lui JB, Altman NH, et al. Essential and non-overlapping IL-2R $\alpha$-dependent processes for thymic development and peripheral homeostasis of regulatory $\mathrm{T}$ cells. Nat Commun 2019;10:1037.

48. Koul S, Khandrika L, Pshak T, et al. Oxalate upregulates expression of IL-2R $\beta$ and activates IL-2R signaling in HK-2 cells, a line of human renal epithelial cells. Am J Physiol Renal Physiol 2014;306:F1039-46. 
49. Krieg C, Létourneau S, Pantaleo G, et al. Improved IL-2 immunotherapy by selective stimulation of IL-2 receptors on lymphocytes and endothelial cells. Proc Natl Acad Sci U S A 2010;107:11906-11.

50. Lagunas-Cruz MDC, Valle-Mendiola A, Trejo-Huerta J, et al. IL-2 Induces Transient Arrest in the G1 Phase to Protect Cervical Cancer Cells from Entering Apoptosis. J Oncol 2019;2019:7475295.

51. Arumugam P, Carroll K, Berceli S, et al. Expression of a functional IL-2 receptor in vascular smooth muscle cells. J Immunol 2019;202:694-703.

52. Wang S, Zhang Z, Yin Z, et al. Anti-IL-2 receptor antibody decreases cytokine-induced apoptosis of human renal tubular epithelial cells (TEC). Nephrol Dial Transplant 2011;26:2144-53.

53. Erkers T, Solders M, Verleng L, et al. Frontline Science: Placenta-derived decidual stromal cells alter IL-2R expression and signaling in alloantigen-activated T cells. J Leukoc Biol 2017;101:623-32.

54. Woodward JE, Bayer AL, Baliga P. Enhanced allograft survival via simultaneous blockade of transferrin receptor and interleukin-2 receptor. Transplantation 1999;68:1369-76.

55. Taber DJ, McGillicuddy JW, Bratton CF, et al. Cytolytic induction therapy improves clinical outcomes in africanamerican kidney transplant recipients. Ann Surg

Cite this article as: Cao Q, Li Y, Li Y, Li L. miR-151$5 \mathrm{p}$ alleviates corneal allograft rejection by activating PI3K/ AKT signaling pathway and balancing Th17/Treg after corneal transplantation via targeting IL-2Ra. Ann Transl Med 2021;9(18):1410. doi: 10.21037/atm-21-2054
2017;266:450-6.

56. Yin N, Wang Y, Lu X, et al. hPMSC transplantation restoring ovarian function in premature ovarian failure mice is associated with change of Th17/Tc17 and Th17/ Treg cell ratios through the PI3K/Akt signal pathway. Stem Cell Res Ther 2018;9:37.

57. Thériault M, Roy O, Brunette I, et al. Physiological pressure enhances the formation of tight junctions in engineered and native corneal endothelium. Exp Eye Res 2019;179:102-5.

58. Muhammad R, Peh G, Adnan K, et al. Micro- and nanotopography to enhance proliferation and sustain functional markers of donor-derived primary human corneal endothelial cells. Acta Biomater 2015;19:138-48.

59. Oh TW, Park KH, Jung HW, et al. Neuroprotective effect of the hairy root extract of Angelica gigas NAKAI on transient focal cerebral ischemia in rats through the regulation of angiogenesis. BMC Complement Altern Med 2015;15:101.

60. Yu J, Li C, Ding Q, et al. Netrin-1 ameliorates blood-brain barrier impairment secondary to ischemic stroke via the activation of PI3K pathway. Front Neurosci 2017;11:700.

(English Language Editor: K. Brown) 
A

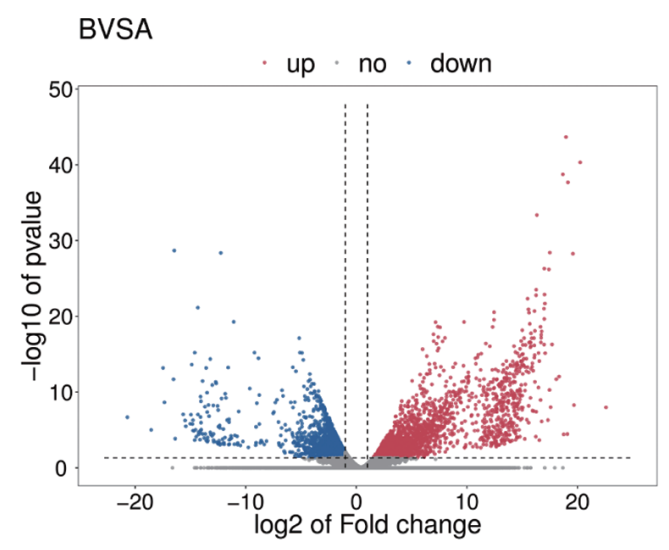

C

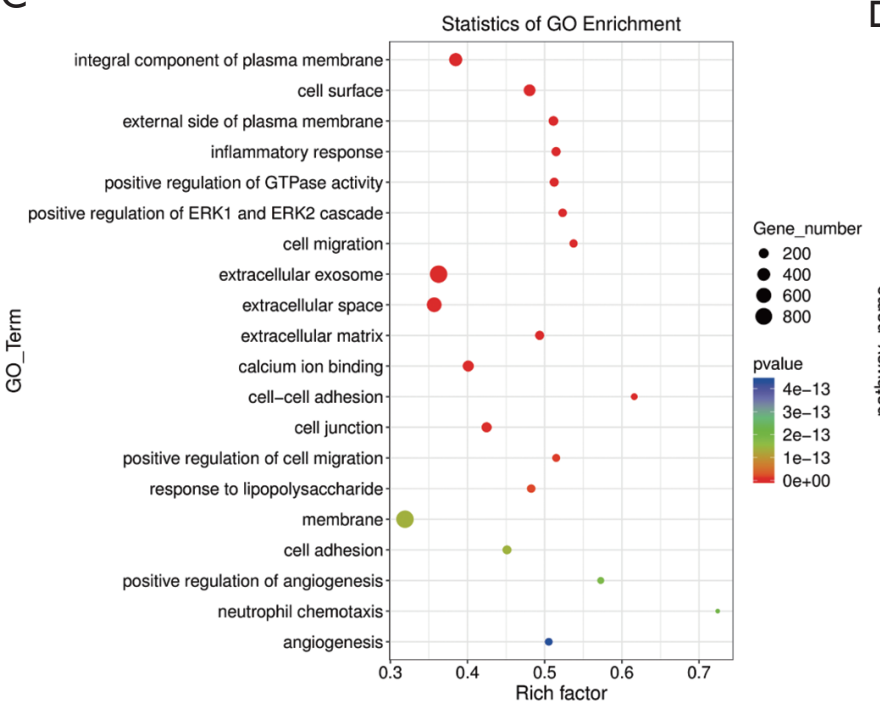

B

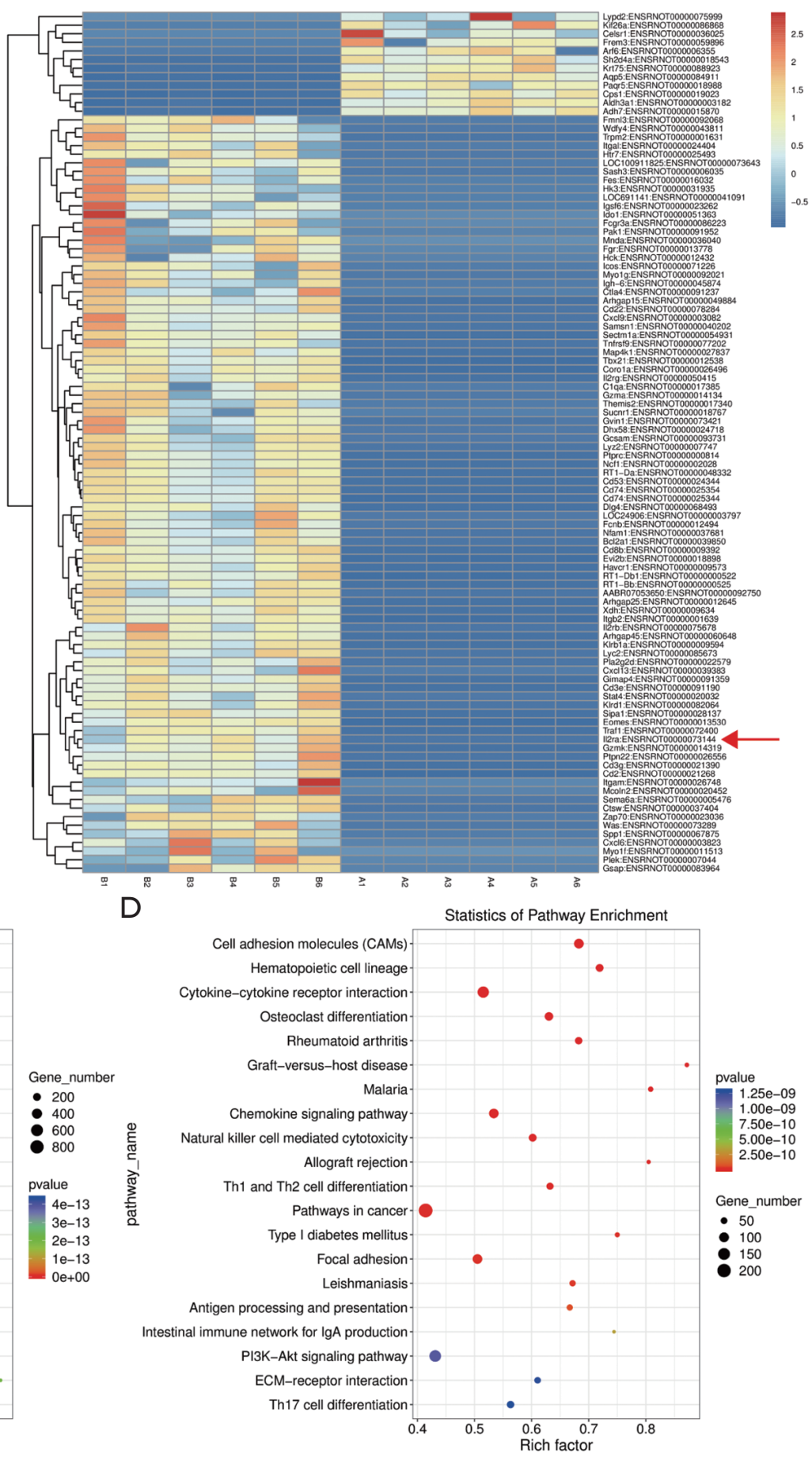

Figure S1 Integrated analysis of differentially regulated mRNAs. (A) Volcano plot of differentially expressed mRNAs (DEGs). X-axis indicates $\log 2$ (fold change). Y-axis indicates $-\log 10$ (P value). Blue represents downregulated mRNAs. Red represents upregulated mRNAs. Gray indicates no significantly differentially expressed mRNAs. (B) Heat map of DEGs ( $\mathrm{P}<0.05)$. There were 4,279 mRNAs with a significant change in CGR, including 2,246 and 2,033 upregulated and downregulated, respectively. (C) Top 20 enriched GO biological processes of DEGs. (D) Top 20 enriched KEGG pathways of DEGs. CGR, corneal graft rejection; GO, gene ontology; KEGG, Kyoto Encyclopedia of Genes and Genome. 
Table S1 Criteria of rejection after corneal transplantation

\begin{tabular}{llll}
\hline Score & Graft opacity & Graft edema & Graft neovascularization \\
\hline 0 & Transparent without turbidity & No edema & No CNV \\
1 & Slightly turbid & $\begin{array}{l}\text { Corneal stroma slightly edematous and } \\
\text { thickened }\end{array}$ & CNV around implantation bed \\
2 & Opacity increased, but iris texture still visible & Diffuse corneal stromal edema & Neovascularization extends to \\
periphery of the graft
\end{tabular}

Table S2 PCR primers used in this study

\begin{tabular}{|c|c|c|}
\hline Gene & Forward primer sequence (5'-3') & Reverse primer sequence (5'-3') \\
\hline $\operatorname{miR}-26 a-5 p$ & TGCGCAACATCACTGCAAGTCT & CCAGTGCAGGGTCCGAGGTATT \\
\hline $\operatorname{miR}-200 b-5 p$ & CATCTTACTGGGCAGCATTGGA & CAGTGCGTGTCGTGGAGT \\
\hline$m i R-374-3 p$ & TATAATACAACCTGATAAGTG & GAACATGTCTGCGTATCTC \\
\hline $\operatorname{miR}-452-5 p$ & AGCGCGAACTGTTTGCAGAGGA & ATCCAGTGCAGGGTCCGAGG \\
\hline $\operatorname{miR}-542-3 p$ & UGUGACAGAUUGAUAACUGAAA & GTGCAGGGTCCGAGGT \\
\hline$m i R-134-5 p$ & ACACTGCATCCTGGCAАTTC & CGTGGTGAATCGAGACTCAC \\
\hline$m i R-219 a-5 p$ & GGTGATTGTCCAAACGG & CAGTGCGTGTCGTGGA \\
\hline $\operatorname{miR}-501-3 p$ & СTGСтCTGCTCGTCСTCTCT & СТССTGTCСТСАСАTGCAGA \\
\hline$m i R-101 a-3 p$ & GCGCGCGCGTACAGTACTGTGATA & ATCCAGTGCAGGGTCCGAGG \\
\hline $\operatorname{miR}-505-3 p$ & GCGAGCACCGTCAACACT & TGGTGTCGTGGAGTCGGC \\
\hline $\operatorname{miR}-204-5 p$ & TCССТTСССТTTGTСАТССТ & GTGCGTGTCGTGGAGTCG \\
\hline $\operatorname{miR}-382-3 p$ & ATCCGTGAAGTTGTTCGTGG & TATGGTTGTAGAGGACTCCTTGAC \\
\hline $\operatorname{miR}-874-3 p$ & GAACTCCACTGTAGCAGAGATGGT & САТТТТТТССАСТССТСТТСТСТС \\
\hline $\operatorname{miR}-324-5 p$ & CGTGAATGATAGTGAGGAAC & GTGAACGATTTGCCACACACA \\
\hline $\operatorname{miR}-363-3 p$ & GCCGAGAATTGCACGGTATC & CTCAACTGGTGTCGTGGA \\
\hline
\end{tabular}

